\title{
Thermal Resistance of Airspaces and Fibrous Insulations Bounded by Reflective Surfaces
}

United States Department of Commerce

National Bureau of Standards

Building Materials and Structures Report 151 


\section{BUITDING MATERIALS AND STRUCTURES REPORTS}

On request, the Superintendent of Documents, U. S. Government Printing Office, Washington. 25, D. C., will place your name on a special mailing list to receive notices of new reports in this series as soon as they are issued. There will be no charge for receiving such notices.

If 100 copies or more of any report are ordered at one time, a discount of 25 percent is allowed. Send all orders and remittances to the Suprerintendent of Documents, U. S. Government Prinding Ofice, Washington $25, D . C$.

The following publications in this series are available by purchase from the Superintendent of Documents at the prices indicated:

BMS1

BMS2

BMS8

BMS4

BMS5

BMS6

BMSt

BMSE

BMS9

BMS10

BMS1,

BMS12

BMS13

BMS14

BMS15

BMS16

BMSI7

BMS18

BMS19

BMS20

BMS2I.

BMS22

BMS23

BMS24

BMS25

BMS26

BMS27

BMS28

BMS29.

BMSBO

BMS31

BMS32

BMSB3

BMS34

BMS35

BMS36

BMS37
Research on Building IVaterials and Structures for Use In Low-Cost Iousing-

Methods of Determining the Structural Properties of Low-Cost House Constructions

Suitability of Fiber Insulating Lath as a Plaster Base

Accolerated Aging of Fiber Building Boards $\ldots$

Structural Propertios of Six Masonry Wall Constructions

Survey of Roofing Materials in the Southeastern States.

Water Permeability of Masonry Walls.

Methods of Investigation of Surface Treatment for Corrosion Protection of Steel.

Structural Properties of the Insulated Steel Construction Co. "s "Prameless-Steel" Constructions for Walls, Partitions, Floors, and Roofs.

Structural Properties of One of the "Koystone Bearn Steel Floor" Constructions Sponsored by the $\mathrm{H}$. $\mathrm{H}$. Robertson Co

Structural Properties of the Curren Fabribone Comporation's "Fabribome" Construc-

tions for Walls and Partitions Roofs Sponsored by Steel Buildings, Inc

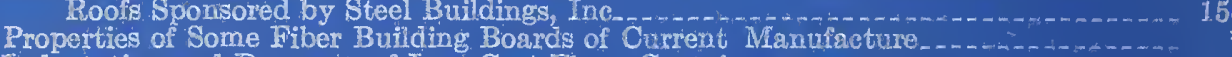

Indentation and Recovery of Low-Cost Floor Coverings.
Structural Properties of "Wheeling Long-Span Steel Floor" Consuruction Sponsored by the Wheeling Corrugating Co

Structural Properties of a "Tilecrete" Floor Constmetion Sponsored by Tilecrete Wloons, Inc.

Sound Insulation of Wall and Floor Constructions
Structural Properties of "Prefab" Constructions for Walls, Partitions, and "Iloors Sponsoned by Harnischfeger Corporation.

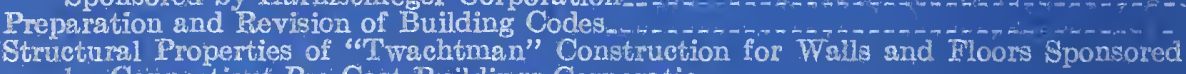
by Connecticut Pro Cagt Buildinge Corporation

Structural Properties of a Concrete-Block Cavity-Wall Construction Sponsored by the
National Concrete Masonry Association Structural Properties of "Dun-Ti-Stone" Wall Construction Sponsored by the W. W.

Suructural Properties of a Brick Cavity-Wall Construction Sponsoned by the Brick Mraufacturers Association of New York, Inc

Structural Properties of a Reinforced-Brick Wall Construction arid a Brick-Tile CavityWall Construction Sponsored by the Structural Clay Products Institute

Structural Properties of Conventional Wood-ITrme Constructions for Walls, Partitions, Floors, and Roofs.

Structural Properties of "Nelson Pre-Cast Concrete Foundation" Wall Constrution. Sponsored by the Nelson Cement Stone Co., Inc

Structural Properties of "Bender Steel Home" Wall Construction Sponsored by the Bender Body Co

Backfow Prevention in Over-Rim Water Supplies

Survey of Roofing Materials in the Nombeastera States...

Structural Properties of a Wood-Frame Wall Construction Sponsored by the Douglas Fiv Plywood Association.

Structural Properties of "Insulite" Wall and "Insulite" Partition Constructions Sponsored by The Insulite Co.

Structural Properties of Two Brick-Concrete-Block Wall Constructions and a Concrote-Block Wall Construction Sponsored by the National Conerete Masonry Assogiation

Plastic Calking Materisils

Performance Test of Floor Coverings for Use in Low-Cost Bousing: Part 1 .

Stability of Sheathing Papors as Determined by Accelerated Aging -

Structural Properties of Wood-Frame Wall, Partition, Floor, and Roof Constructiona With "Red Stripe" Lath Sponsored by The Weston Paper and Manufacturing Co Structural Properties of "Palisade Homes" Constructions for Walls, Partitions, ard Floors Sponsored by Palisade Homes.

*ust of print.

fSuperiseded by BMS144.

†Supersoded by BMS110.

[List continued on cover page ru] *k 106. 


\title{
Thermal Resistance of Airspaces and Fibrous Insulations Bounded by Reflective Surfaces
}

\author{
H. E. Robinson, L. A. Cosgrove, and F. J. Powell
}

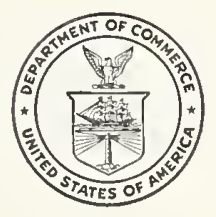

Building Materials and Structures Report 151

Issued November 14, 1957 


\section{Contents}

1. Introduction

2. Apparatus and test proeedure

3. Test panels and insulation $\ldots$

4. Method of presenting results

4.1. Definition of symbols _.........

4.2. Computation of results

5. Results and discussion

5.1. Panels insulated only with aluminum-foil membranes...............

a. Effect of moisture condensation

b. Effect of air circulation between tandem airspaces through holes in the dividing aluminum-foil membrane

c. Effect of nonuniformity of thickness on the thermal resistance of airspaces

d. Effect of minute perforations in a foil membrane forming tandem airspaces, and some results indicating an effect due to radiation from the wood framing

5.2. Panels insulated with fibrous insulations in combination with reffective surfaces

a. Semirigid mineral-wool board insulation without and with reflective surfaces

b. Flexible lightweight 1/4-in. mineral-wool blanket with aluminum-foil membrane on warm side-four methods of installation

c. Commercial 2-in. mineral-wool blanket, foil-enclosed and kraft-enclosed

6. Summary of result clos

7. Appendix

7.1. Method of ealentating a

. Raefficient for combined

7.2. Range of experimental conditions at which convection-conduction coefficients were determined 


\title{
Thermal Resistance of Airspaces and Fibrous Insulations Bounded by Reflective Surfaces
}

\author{
II. E. Robinson, L. A. Cosgrove, ${ }^{1}$ and F. J. Powell
}

\begin{abstract}
Observed insulating values are presented for 28 test panels, of which 23 were insulated with reflective nembranes used alone or in combination with fibrous insulations. The panels were tested at five different orientations corresponding to use as walls, ceilings, or floors. The observed insulating values of panels are compared with calculated values based on a method and data developed in previous work at the National Bureau of Standards, and summarized in an appendix to this report. Observed values for panels agreed within 10 percent, in most cases, with calculated values. Departures of observed from calculated values are attributed to such factors as nonuniformity of airspace thickness, moisture condensation on reflective surfaces, air circulation between tandem airspaces, and effects due to local high conductance at edges of insulations or radiation from framing members.
\end{abstract}

\section{Introduction}

With the publication in 1954 of Housing Research Paper 32, The Thermal Insulating Value of Airspaces, ${ }^{2}$ based on measurements made at the National Bureau of Standards, a method and essential data became available for calculating the thermal conductance of airspaces of uniform thickness for various conditions. It was shown that the total heat-transfer coefficient of an airspace could be separated into two additive coefficients, one a coefficient for heat transfer by radiation which could be calculated with adequate accuracy by a relatively simple method, and the other a coefficient for heat transfer by convection and conduction combined. Experimental values for the convection-conduction coefficient for airspaces of uniform thickness were given as a function of orientation, direction of heat flow, thickness, temperature difference, and mean temperature.

The method of calculation, and the necessary data, are summarized in the appendix. These data were obtained by measurements made on panels containing one airspace or two tandem airspaces of uniform thickness and no other insulating materials. The derived coefficients of heat transfer by convection and conduction combined represent experimental values for airspaces of an exemplary or model type, characterized by smooth, flat, parallel surfaces relatively uniform in temperature.

The insulating values of airspaces with one or more highly reflective surfaces were found in the previous work to be of such magnitude that it appeared the insulating effect of installations of fibrous insulations of blanket, batt, or board form with adjoining airspaces could be very considerably augmented by making their surfaces highly reflective, especially for cases of downward heat

1 Aluminum Company of America.

2 U. S. Government Printing Office, Washington 25, D. C. (1954). flow. However, it was not known how much the insulating value of an airspace formed in this way in combination with fibrous insulations might depart from that of the exemplary type of airspace, as a result of possible changes in the convective coefficient of the airspace due to nonuniformity of airspace thickness, local variations in the thickness or conductance of the fibrous insulation, especially near framing members, or other factors.

In order to investigate these and similar matters, a research program was undertaken at the $\mathrm{Na}$ tional Bureau of Standards with the financial assistance of Aluminum Company of America, which also made available for the program the services of one of the authors.

The major objectives of the program were (a) to determine the applicability of the data given in the appendix for calculating the insulating effect of combinations of reflective and fibrous insulation, (b) to ascertain experimentally the insulating values of particular reflective and fiblous insulation combinations installed in particular ways, and (c) to investigate in some measure the effects on the insulating value of airspaces of condensation of moisture on reflective surfaces, circulation of air between spaces through holes in the dividing membrane or matcrial, and of nonuniformity of airspace thickness. The complete results of the program and discussions of them are given.

\section{Apparatus and Test Procedure}

The heat-transfer measurements were made on test panels in the rotatable guarded hot box apparatus at the National Bureau of Standards. The apparatus, designed for panels $5 \frac{1}{2}$ by $8 \mathrm{ft}$ in area, up to $1 \mathrm{ft}$ thick, was mounted ou horizontal trunnions, which allowed the position of the plane of the panel to be rotated to any angle up to $90^{\circ}$ from the vertical in cither direction. 


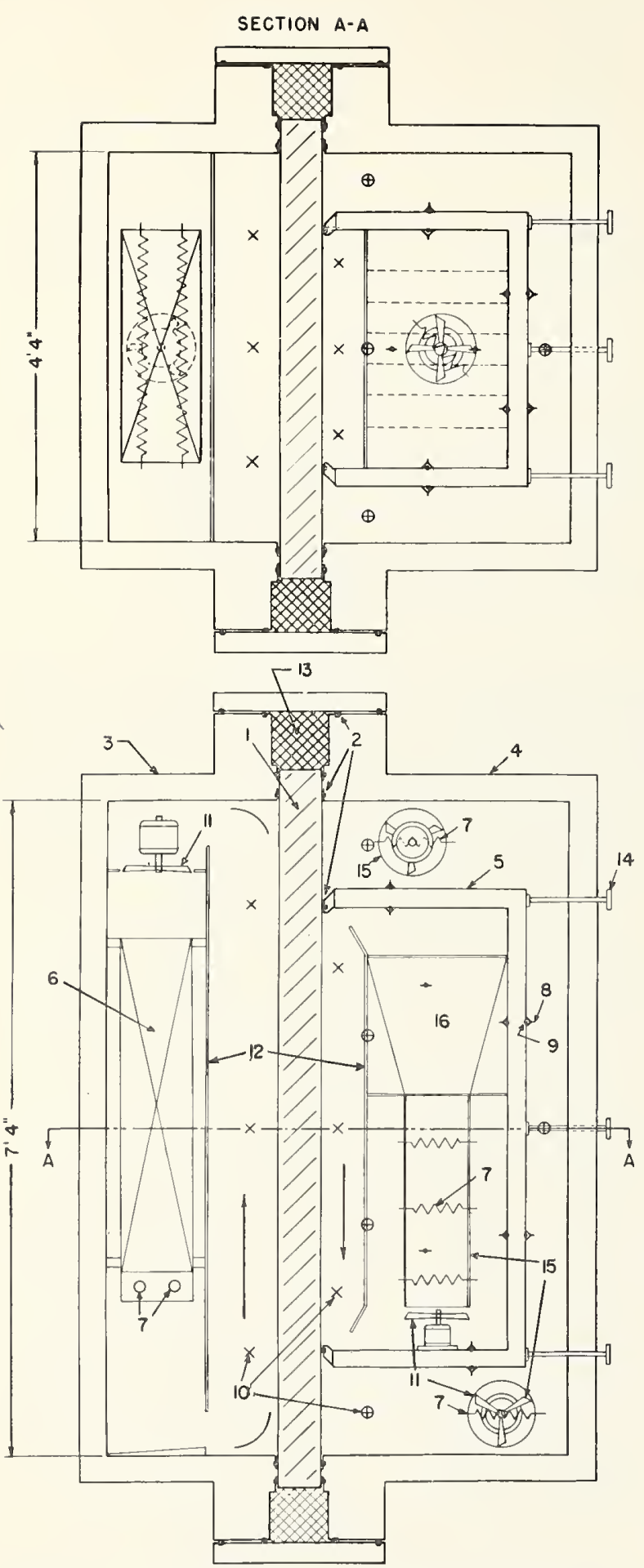

FIQURE. 1. Schematic drawing of rotatable guarded hotbox.

1, Test panel; 2, rubber gaskets; 3, cold box; 4, guard box; 5, metering box; 6 , refrigerating coil; 7 , electric heaters; 8 , air-compound thermocouples; 9, surface-compound thermocouples; 10, air-temperature thermocouples; 11, air-circulating fans; 12 , baffies; 13 , edge insulation; 14, compressionspring handwheels; 15 , heater ducts; 16 , meter heat diffuser.
The hot box apparatus conformed substantially to the requirements of ASTM C 236-54T, Method of Test for Thermal Conductance and Transmittance of Built-Up Sections by Means of the Guarded Hot Box ('Tentative), except for the additional feature of rotatability on trunnions.

As shown schematically in figure 1, the apparatus consisted of a cold box (3) and a warm, or guard, box (4), between which the test panel (1) was interposed. The two boxes were held together by means of long bolts engaging lugs around the periphery of the joint. The guard box contained a metering box (5), the open face of which was pressed against the face of the panel by four compressing springs (14). The contact between the metering box and the panel was made substantially aintight by the rubber gasket (2), which bounded the centrally located "metering area" of the panel, a rectangle $60 \mathrm{in}$. long and 32 in. wide, through which heat flow was measured during a test. One-half of the width of the contact surface of the gasket was within the metering area. The remainder of the panel area constituted a "guard," through which heat flow was not measured, but which protected the metering area against lateral heat flow. Insulation (13) was placed at the edges of the panel to further reduce lateral heat flow.

During measurements, the metering box was held at the selected temperature by means of electric heaters (7) controlled by a sensitive thermistor in the box. The guard-box temperature was automatically made to approximate that of the metering box by the use of a compound thermocouple (8) consisting of 10 differential thermocouples in series, the junctions of each pair being located opposite each other, 1 in. from the inside and outside surfaces of the metering box. The emf from the compound thermocouple (8) actuated a relay that controlled the heat input to the guard box as required. The cold box was held at the desired lower temperature by means of a refrigerating evaporator coil (6) and a small electric heater (7) controlled by a thermistor in the box. The air in each box was circulated continuously by fans (11). In the metering and cold boxes, the circulated air was constrained by baffles (12) to pass downward and upward, respectively, along the surface of the panel. The direction of airflow on each side was the same as would result from natural convection at the panel faces. The average air velocity in the metering-box baffle space was about $40 \mathrm{ft} / \mathrm{min}$, and in the cold-box baffle space was about $90 \mathrm{ft} / \mathrm{min}$. Air temperatures in the baffle spaces and at other locations in the boxes were measured by means of thermocouples (10), as indicated. These thermocouples, and all others used in these tests, were made with No. 30 AWG copper and constantan wires. 
All electrical input to the heaters, fan, and other devices in the metering box was measured by means of a calibrated watthour meter readable to 1 whr. Under steady temperature conditions, with the guard-box temperature maintained so that there was no average temperature difference and thus no heat transfer through the meteringbox walls, all of the heat supplied to the metering box was transmitted to the cold box, through the known metering area $\left(13.33 \mathrm{ft}^{2}\right)$ of the panel. The average rate of heat flow per square foot of metering area could thus be determined.

To be able to correct for any actual small heat transfer between the metering box and the surrounding guard box, a compound thermocouple (9) was used, consisting of 10 series-connected differential thermocouples with the junctions of each pair cemented opposite each other in grooves in the surfaces of the metering box. The positions of the pairs were similar to those of the compound thermocouple (8) used to control the heat input to the guard box. It was determined by preliminary calibration measurements and by observations during the tests that the heat flow between the metering and guard boxes was less than 2.8 Btu/hr, or 0.21 (Btu/hr) per square foot of panel metering area for most tests. Although this was only a small percentage of the total heat input, the observed heat input for each test was corrected for such transfer.

The test observations used in computing results were made only after steady temperature conditions had been attained. The duration of the steady-state test period was in most cases more than $20 \mathrm{hr}$, and in only two cases less than $14 \mathrm{hr}$. All thermocouples were read by means of a manually operated potentiometer with which temperature changes of less than $0.05 \mathrm{deg} F$ were detectable. The steadiness of temperatures for more than 95 percent of the tests was such that average panel surface temperatures, as indicated by 10 thermocouples on each face, did not vary more than $0.3 \mathrm{deg} F$ during the test period.

The average conductance of the panel was calculated from the average net heat flow in to the panel per square foot of metering area and the average temperature difference between the panel faces. Since the metering area included some of the wood framing around the test airspaces of the panels, a small adjustment was made to allow for the effect of the heat conduction through the wood framing. The adjusted conductance thus obtained represented the average experimental thermal conductance, $C$, of the panel space including all installed insulation. In most tests, thermocouples were placed on the dividing membrane, or on the warm and cold surfaces of fibrous insulating blankets, for measurement of surface temperatures with which the conductance of tandem components could be determined.

\section{Test Panels and Insulation}

The thermal conductances (and resistances) of 28 different test panels were determined by using three test-panel frames, $\mathrm{A}, \mathrm{B}$, and $\mathrm{C}$ in figure 2 . The panel frames were symmetrical about both center lines. Frames $\mathrm{A}$ and $\mathrm{C}$ were constructed from nominal 2 - by 4 -in. and 2- by 8 -in. clear fir, respectively. Frame B was formed from A yb the addition of the center stud.

The metering area was the 32 - by 60 -in. rectangle centered on the panel. This included half of the wood bounding the test space and the center stud, which totaled about 5, 9, and 12 percent of the test area for panels $\mathrm{A}, \mathrm{B}$, and C, respectively. The remainder of the panel constituted a guard area, which was insulated in a manner similar to the test area in all possible respects.

The faces of the panels were made of 19 or 21 gage galvanized sheet steel, painted on both surfaces with flat white paint having an estimated average emittance of 0.90 . On both faces of the panels, the sheet covering the metering area was separated by a $1 / 8$-in. gap from the sheets over the guard airspaces to reduce lateral heat conduction into or out of the metering area. To seal the airspaces, the face sheets were screwed to the frames over $1 / 16$-in. felt strips glued to the wood.

The temperatures of the sheet-metal faces were measured with thermocouples soldered to the outer surface of the sheet covering the metering area at 10 positions on each face, located as shown in $\mathrm{F}$ of figure 2. The thermocouple leads were cemented to the face of the sheet until they reached a takeoff point at midlength of the sheet. Both surfaces of each sheet were painted white after the thermocouples were attached.

Table 1 and figures 2 and 3 give particulars as to the dimensions, configurations, etc., of the panels and insulations tested. The positioning of membrane or blanket forms of insulation and the resultant airspaces are indicated by the sections $\mathrm{A}-\mathrm{A}$ shown in figure 3 . The details of attaching the various insulations to the wood framing are shown schematically in the circles of figure 3 , referred to in table 1 . The temperatures of the membrane or blanket surfaces were measured with thermocouples attached, in most cases with aluminum-foil tape, in accordance with one of the five major schemes shown as D, E, F, G, and H of figure 2. In some cases, additional temperatures on the horizontal center line of the metering area were measured with thermocouples placed on the foil membrane or blanket surfaces, as shown in sections $I$ and $K$, and in circles $W, X$, and $Y$ of figure 3.

The total emittances of the surfaces bounding the airspaces were determined, when feasible, by separate measurements made on samples of the materials, most of which were taken from the panels after completion of the test. 
TEST PANEL FRAMES
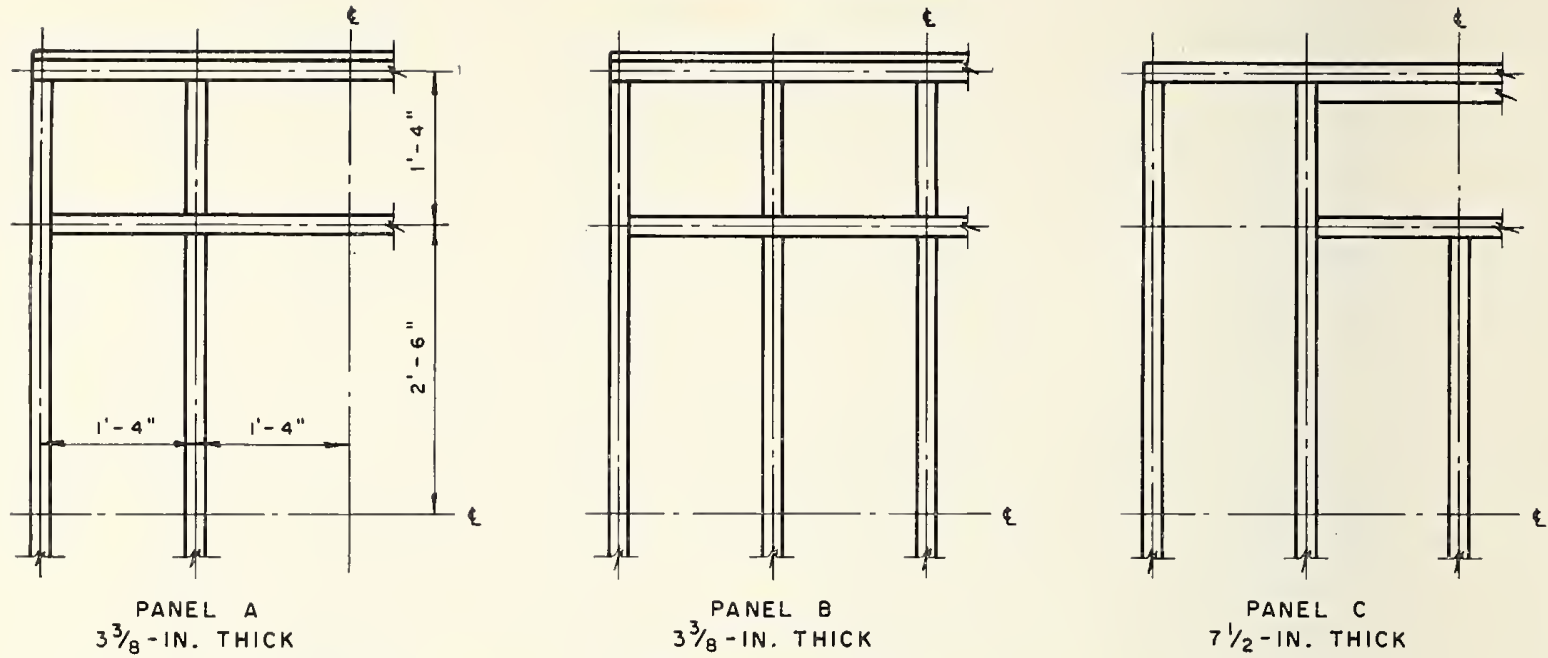

INSULATION THERMOCOUPLE ARRANGEMENTS
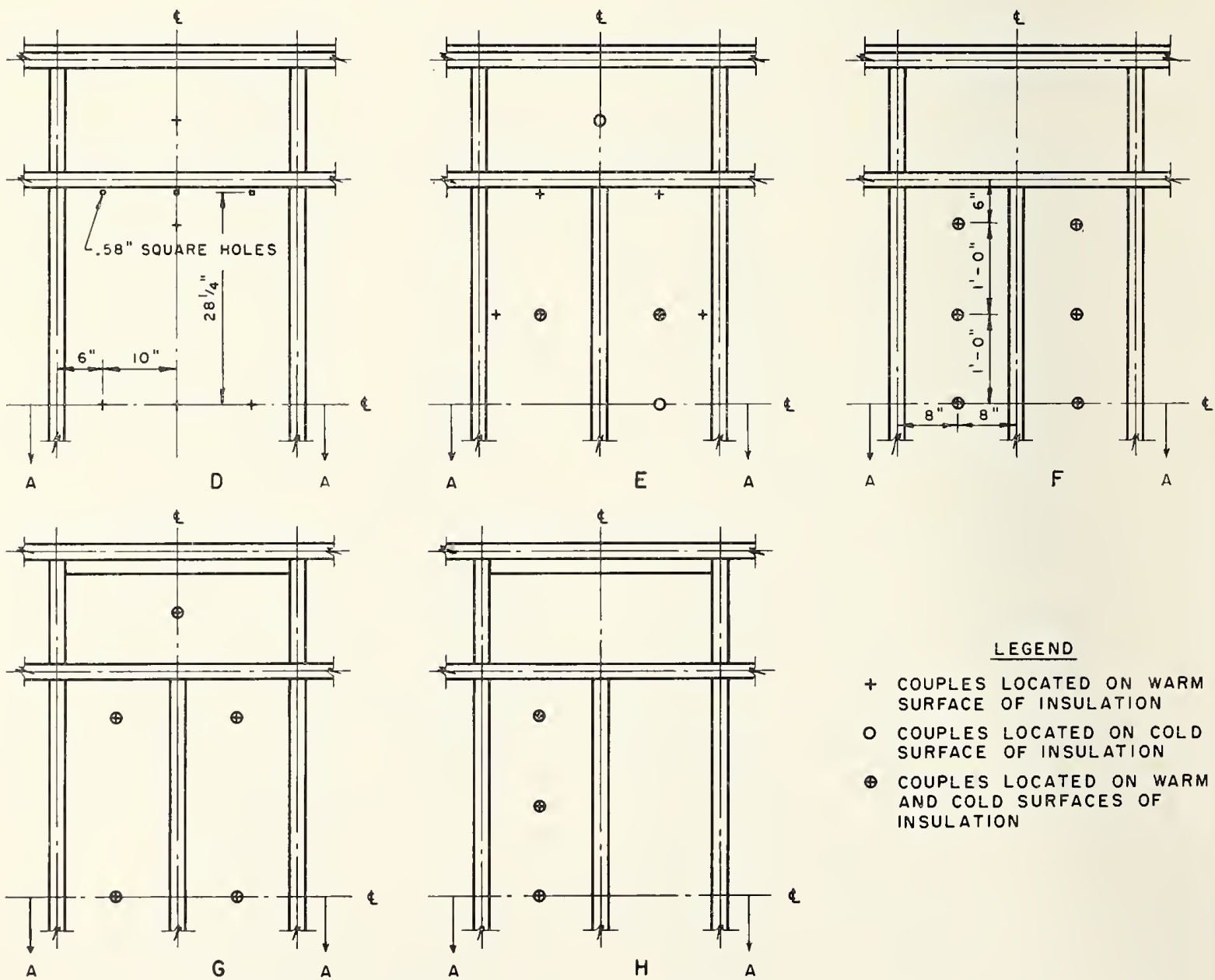

Finure 2. Test-panel frames and insulation thermocouple arrangements. 
TABLE 1. Particulars of test panels

\begin{tabular}{|c|c|c|c|c|c|c|c|c|c|c|}
\hline \multirow{2}{*}{ Panel } & \multirow{2}{*}{$\begin{array}{l}\text { Test-panel } \\
\text { frame, } \\
\text { figure } 2\end{array}$} & \multirow{2}{*}{$\begin{array}{l}\text { Insulation } \\
\text { cross sec- } \\
\text { tion } \mathbf{A}-\mathbf{A} \text {, } \\
\text { figure } 3\end{array}$} & \multirow{2}{*}{$\begin{array}{c}\text { Installation } \\
\text { details, } \\
\text { figure } 3\end{array}$} & \multicolumn{2}{|c|}{$\begin{array}{c}\text { Insulation thermocouple } \\
\text { arrangement }\end{array}$} & \multirow{2}{*}{ Notes } & \multicolumn{2}{|c|}{$\begin{array}{l}\text { Radiation interchange } \\
\text { factor }(E) \text { of airspaces }\end{array}$} & \multirow{2}{*}{$\begin{array}{l}\text { Number of } \\
\text { panel orien- } \\
\text { tations } \\
\text { tested }\end{array}$} & \multirow{2}{*}{$\begin{array}{l}\text { Number } \\
\text { of tests }\end{array}$} \\
\hline & & & & Figure 2 & Figure 3 & & Warm & Cold & & \\
\hline \multicolumn{11}{|c|}{ A. Aluminum foil (0.001 in.) installed as a midspace membrane } \\
\hline $\begin{array}{l}1 \\
2 \\
3 \\
10\end{array}$ & $\begin{array}{l}\mathrm{A} \\
\mathrm{A} \\
\mathrm{A} \\
\mathrm{B} \\
\mathrm{B}\end{array}$ & $\begin{array}{l}\mathrm{I} \\
\mathrm{I} \\
\mathrm{I} \\
\mathrm{K} \\
\mathrm{K}\end{array}$ & $\begin{array}{l}\mathrm{S} \\
\mathrm{S} \\
\mathrm{S} \\
\mathrm{T} \\
\mathrm{U}\end{array}$ & \begin{tabular}{l}
$\mathrm{D}$ \\
$\mathrm{D}$ \\
$\mathrm{D}$ \\
\hdashline
\end{tabular} & $\begin{array}{l}\mathrm{I} \\
\mathrm{I} \\
\mathrm{I} \\
\mathrm{K} \\
\mathrm{K}\end{array}$ & b & $\begin{array}{r}0.03 \\
.03 \\
.03 \\
.03 \\
.03\end{array}$ & $\begin{array}{r}0.03 \\
.03 \\
.03 \\
.03 \\
.03\end{array}$ & $\begin{array}{l}4 \\
3 \\
4 \\
5 \\
5\end{array}$ & $\begin{array}{l}6 \\
3 \\
4 \\
5 \\
5\end{array}$ \\
\hline $\begin{array}{l}15 \\
16 \\
21 \\
29\end{array}$ & $\begin{array}{l}\mathrm{B} \\
\mathrm{C} \\
\mathrm{C} \\
\mathrm{C}\end{array}$ & $\begin{array}{l}\mathrm{K} \\
\mathrm{I} \\
\mathrm{I} \\
\mathrm{I}\end{array}$ & $\begin{array}{l}\mathrm{U} \\
\mathrm{S} \\
\mathrm{S} \\
\mathrm{S}\end{array}$ & F & $\begin{array}{c}\mathrm{K} \\
\mathrm{c} \\
\mathrm{n}\end{array}$ & $\underset{\mathrm{e}, \mathrm{f}}{\mathrm{f}}$ & $\begin{array}{l}.03 \\
.06 \\
.03 \\
.03\end{array}$ & $\begin{array}{l}.03 \\
.06 \\
.03 \\
.03\end{array}$ & $\begin{array}{l}5 \\
5 \\
5 \\
3\end{array}$ & $\begin{array}{r}6 \\
5 \\
10 \\
3\end{array}$ \\
\hline
\end{tabular}

B. Mincral-wool blanket (tbickness, $1 \frac{1 / 4}{\mathrm{in}}$.; density, $0.6 \mathrm{lb} / \mathrm{ft}^{3}$ ) faced on warm surface with aluminum foil

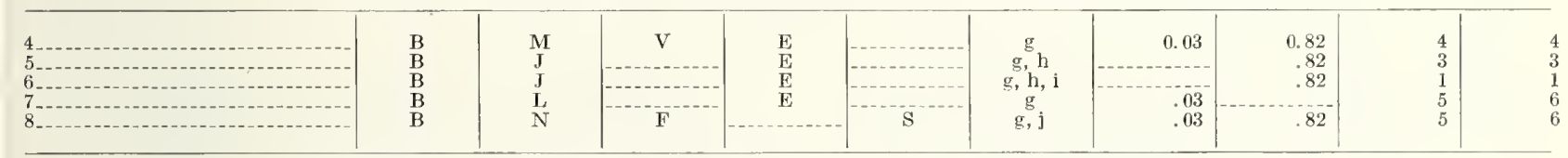

C. Mineral-wool blanket (nominal thickness, 2 in.; density, $1.5 \mathrm{lb} / \mathrm{ft}^{3}$ ) aluminum-foil enclosed ${ }^{1}$ (see note $\mathrm{k}$ )

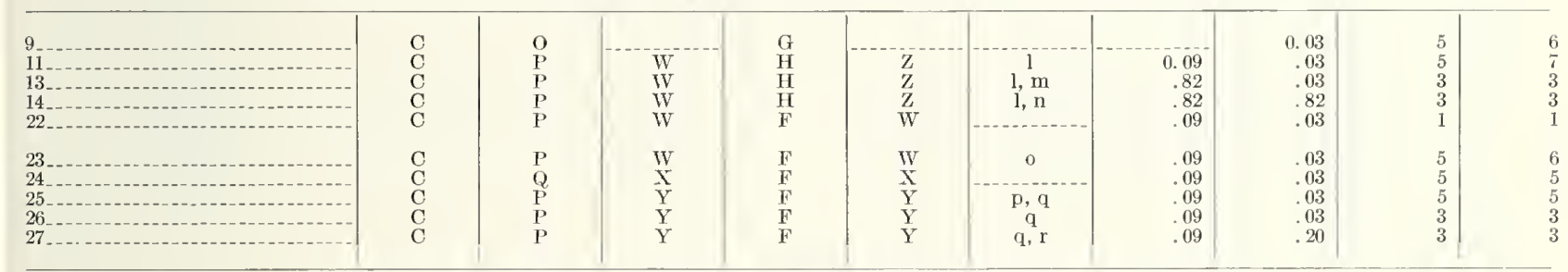

D. Mineral-wool blanket (nominal thickness, 2 in.; density, 1.5 lb/ft ${ }^{3}$ ) kraft-paper cnclosed (see note k)

\begin{tabular}{|c|c|c|c|c|c|c|}
\hline 28 & $\mathrm{C}$ & $\mathrm{P}$ & WV & $\mathrm{F}$ & 0.86 & 5 \\
\hline
\end{tabular}

E. Mineral-wool insulation board (thickness, $11 / 2 \mathrm{in.;}$ density, $9 \mathrm{lb} / \mathrm{ft}^{3}$ ) experimentally faced with aluminum foil in tests 19 and 20

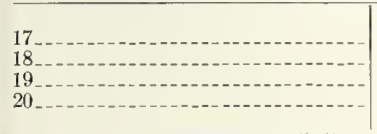

\begin{tabular}{l|l}
$\mathrm{C}$ & $\mathrm{R}$ \\
$\mathrm{C}$ & $\mathrm{R}$ \\
$\mathrm{C}$ & $\mathrm{R}$ \\
$\mathrm{C}$ & $\mathrm{R}$
\end{tabular}

\begin{tabular}{l|l|}
$R$ & \\
$R$ & -1. \\
$R$ & $S$ \\
$R$ & $S$
\end{tabular}

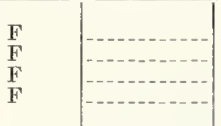

\begin{tabular}{c|}
$\mathrm{s}$ \\
$\mathrm{j}, \mathrm{t}$ \\
$\mathrm{j}, \mathrm{u}$
\end{tabular}

\begin{tabular}{r|}
0.82 \\
.82 \\
.03 \\
.03
\end{tabular}

\begin{tabular}{r|r|r}
\hline 0.82 & 5 & 6 \\
.82 & 5 & 5 \\
.82 & 5 & 6 \\
.03 & 5 & 7
\end{tabular}

a. Panel 2 was panel 1 , sun-dried to remove accumulated moisture.

Notes

b. Six holes, $0.58 \mathrm{in}$. sq, eut at points indicated by squares in $\mathrm{D}$ of figure 2.

c. Dimension $A$ of eircle $U$ in figure 3 equal to 1,2 in.

d. Dimension $A$ of circle $U$ in figure 3 equal to 1 in.

e. No thermocouples on foil or in panel spaces in these tests.

g. Center stud in top and bottom guard sections (see B of fig. 2) removed in these tests.

g. Center stud in top and bottom guard sections (see B of fig. 2) removed in these tests.
h. Like detail of cirele $V$ in figure 3 , except foil stretched tautly against warm surface plate.

h. Like detail of cirele $V$ in figure 3 , except foil stretehed

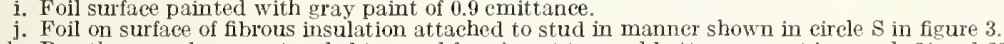

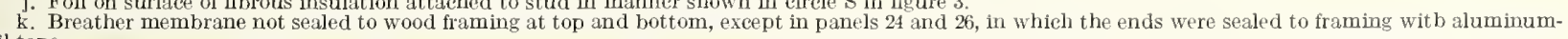
foil tape.

l. Thermocouples shown in cirele $W$ in figure 3 not used in these panels.

$\mathrm{m}$. Foil on warm surface painted with gray paint of 0.9 emittance.

n. Foil on both surfaces painted witb gray paint of 0.9 emittance.

0 . Same as panel 22 , but thermocouples shown in circle IV in figure 3 reattached.

p. Foil breather membrane with foil removed from areas between arrows in circle $Y$ in figure 3.

q. Thermocouples attached to inside of breather membrane with cellophane tape.

r. Foil breatber replaced with paper breather of 0.20 emittance on cold side.

r. Foil breatber replaced with paper breather of 0.20 emittance on cold side.
s. Both surfaces of insulating board painted with flat wbite paint of 0.9 emittanee.

s. Both surfaces of insulating board painted with flat wbite paint of 0.9 emittanee
t. Aluminum foil cemented to the warm surface of the painted board of panel 18 .

t. Aluminum foil cemented to the warm surface of the painted board of panel 18 .
u. Aluminum foil cemented to the cold surface of the painted board of panel 19 .

$\mathrm{v}$. Kraft-foil laminate perforated with 64 holes per square inch.

1 Vapor barrier membrane of foll laminated to kraft with aspbalt; breatber membrane of kraft-foil laminate perforated witb 64 holes per square incb. Foil surfaces were outermost. 
SECTIONS A-A

$3 \frac{3}{8}-$ IN THICK SPECIMENS

I

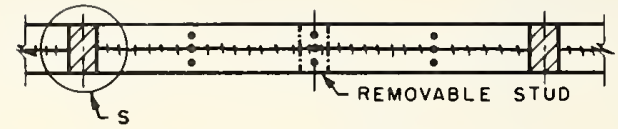

k

$+P / d$ ORU $\checkmark \frac{1}{I_{1 / 4}^{\prime \prime} \text { BLANKET }}$

L $M+1$

$11 / 4$ " BLANKet

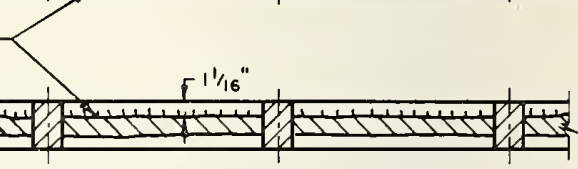

$7 \frac{1}{2}$-IN THICK SPECIMENS
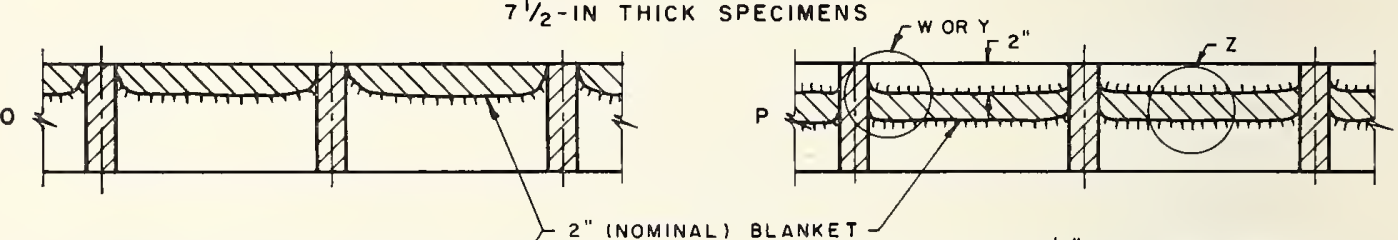

0
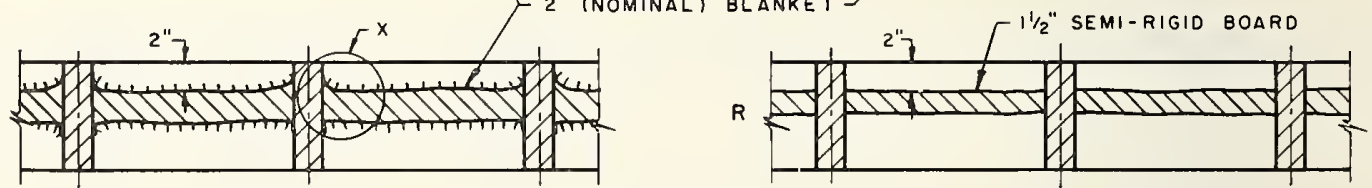

INSTALLATION DETAILS

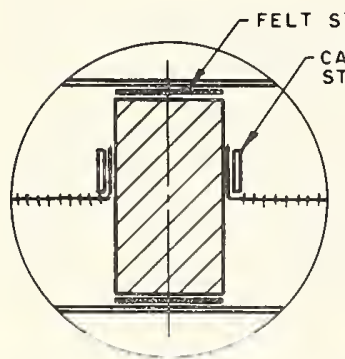

S

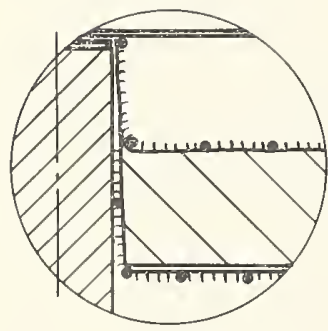

W

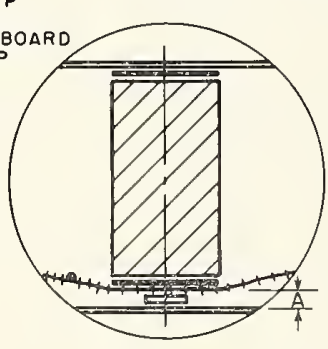

T

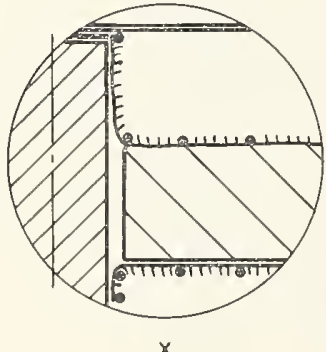

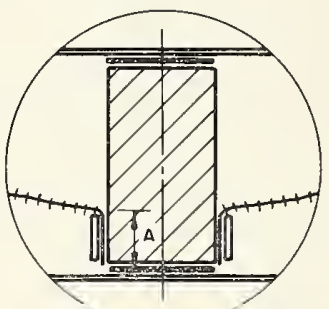

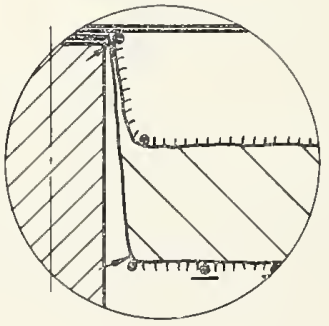

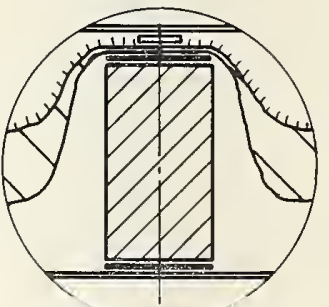

V

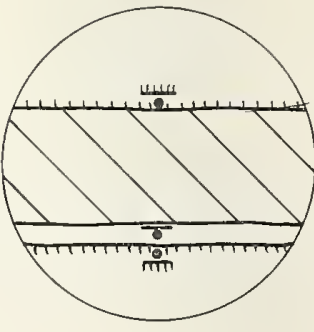

Z

LEGEND

- NON-REFLECTIVE SURFACE

WWW REFLECTIVE SURFACE (ONE SIDE)

HHHH REFLECTIVE SURFACE (BOTH SIDES)

- THERMOCOUPLE ON MEMBRANE SURFACE

(FOIL COVERED FOR REFLECTIVE SURFACES)

FIGURE 3. Details of specimens and installations. 


\section{Method of Presenting Results}

The results of this investigation are presented in terms of thermal resistance (the reciprocal of thermal conductance), the unit of which is deg $\mathrm{F}$ per $\left(\mathrm{Btu} / \mathrm{hr} \mathrm{ft}^{2}\right)$. Resistances, rather than conductances, are used because they are additive for tandem components, and thus comparisons of resistances indicate directly the relative insulating effects of various components. Further, resistances are the quantities actually used in most computations of the insulating effect of constructions.

The experimentally determined thermal resistances $(R)$ of the test panels and component airspaces and other insulations are listed in tables 2 to 8 . Included in the tables are calculated resistances $\left(R^{\prime}\right)$ for the temperature conditions that existed experimentally, based on the method and data given in the appendix. The experimental and calculated values of resistance are conveniently compared by taking their ratio $R / R^{\prime}$. The differences between the observed and calculated resistances can be obtained from the tabulated values.

For panels containing thick fibrous blankets in addition to airspaces, the temperature differences across the airspaces were often small (10 deg $\mathrm{F}$ or less). Small errors in the measured surface temperatures could lead to a quite large percent age error in the temperature difference and therefore in the experimental airspace resistance.

The observed temperatures and temperature drops of the tandem components of a test panel can be deduced from the observed resistances and the tabulated values of panel mean temperature and temperature difference for each test.

\subsection{Definition of Symbols}

$a=$ fraction of area of a perforated membrane represented by apertures.

$C=$ experimentally determined thermal conductance; the time rate of heat flow through a unit area of a panel or panel component (adjusted to exclude the effects of wood framing) from one of its surfaces to the other per unit temperature difference between the two surfaces. Conductances are expressed herein in $\mathrm{Btu} / \mathrm{hr} \mathrm{ft}^{2}$ (deg F).

$C^{\prime}=$ calculated thermal conductance; calculated on the basis of the method and data given in the appendix.

$C_{t}=$ over-all panel thermal conductance; the value determined from the test data, including the effects of wood framing.

$e=$ surface hemispherical total emittance; the rat of of the total radiant flux density emitted by a surface as a consequence of its temperature to that emitted by a bla $k$ body at the same temperature.
$E=$ radiation interchange factor of an airspace; the combined effect of the surface emittances, $e$, of the boundary surfaces of an airspace, calculated in accordance with eq (3) of the appendix.

$h_{c}=$ convection-conduction coefficient; one component of the calculated thermal conductance, $C^{\prime}$.

$h_{r}=$ linear radiation coefficient; a factor in one component of the calculated thermal conductance, $C^{\prime}$.

$l=$ the thickness of an airspace, inches.

$R=$ observed thermal resistance; the reciprocal of the experimental thermal conductance, C. Resistances are expressed herein in deg $\mathrm{F}$ per (Btu/hr ft ${ }^{2}$ ).

$R^{\prime}=$ calculated thermal resistance; the reciprocal of the calculated thermal conductance, $C^{\prime}$.

$R / R^{\prime}=$ the ratio of the experimental and calculated resistances of the test pancl or any of its components.

$\theta=$ the temperature difference between the surfaces of a panel or any of its component elements, deg $\mathrm{F}$.

\subsection{Computation of Results}

An illustration of the method of computation of the experimental resistance $(R)$ and of the callated value $\left(R^{\prime}\right)$ is given below.

For computational reasons, this illustration is worked out in terms of thermal conductances, the final results being converted to resistances as shown. The following pertinent experimental data were obtained in test 117 (table 7 ):

a. Average temperature of the warm surface plate $=79.5^{\circ} \mathrm{F}$.

b. Average temperature of the warm insulation surface $=63.8^{\circ} \mathrm{F}$.

c. Average temperature of the cold insulation surface $=13.1^{\circ} \mathrm{F}$.

d. Average temperature of the cold surface plate $=-3.5^{\circ} \mathrm{F}$.

e. Average power input to metering box $=$ $30.30 \mathrm{w}$.

f. Heat transfer from metering box to guard box, based on average emf of compound differential thermocouple $=0.79 \mathrm{w}$.

The adjusted power input (29.51 w), converted to the desired units by the factor 0.2513, was divided by the temperature difference between the panel faces to yield the over-all thermal conductance $\left(C_{t}\right)$ of the panel:

$$
C_{t}=\frac{29.51 \times 0.2513}{79.5-(-3.5)}=0.0893 \mathrm{Btu} / \mathrm{hr} \mathrm{ft}^{2}(\mathrm{deg} \mathrm{F})
$$

This value includes the effect of heat flow in the wood framing within the metcring area according to the equation 
$C_{t}=C_{\text {wood }} \times \frac{\text { area of wood }}{\text { total area }}+C \times \frac{\text { area of space }}{\text { total area }}$,

where $C$ is the panel conductance aljusted to remove the effects of the wood framing. In this panel, $C_{\text {wood }} \times$ (area of wood/total area) equaled 0.0156 and (area of space/total area) equaled 0.883 , thus:

$$
C=\frac{0.0893-0.0156}{0.883}=0.0835 \mathrm{Btu} / \mathrm{hr} \mathrm{ft}^{2}(\mathrm{deg} \mathrm{F})^{\prime}
$$

$R=11.98 \mathrm{deg} F$ per $\left(\mathrm{Btu} / \mathrm{hr} \mathrm{ft}^{2}\right)$.

The resistances $(R)$ of components of the panel were computed by means of the relation $R_{\text {component }} / R_{\text {panel }}=\theta_{\text {component }} / \theta_{\text {panel }}$, where $\theta$ is the observed temperature drop across the component or panel. For this test, the resistances of the warm and cold airspaces and the fibrous blanket were $2.27,2.39$, and 7.32 , respectively.

The calculated values $\left(R^{\prime}\right)$ for the panel and components were computed using the method and data given in the appendix and the pertinent observed data from test 117 , as follows:

a. Direction of heat flow-horizontal.

b. Thicknesses of the airspaces-warm, 2 in.; cold, $3 \frac{1 / 2}{2}$.

c. Values of $E$ for the airspaces-warm, 0.09 ; cold, 0.03 .

d. 'Temperature differences across the airspaccs-warm, $15.7 \mathrm{deg} \mathrm{F}$; cold, $16.6 \mathrm{deg} \mathrm{F}$.

e. Mean temperatures of the airspaces-warm, $71.7^{\circ} \mathrm{F}$; cold, $4.8^{\circ} \mathrm{F}$. 7.32 .

f. Experimental resistance of fibrous blanket=

The value of $\theta l^{3}$ was 126 for the warm space and 712 for the cold space, for which figure 6 yielded (after division of $\left(h_{c} l\right)_{50}$ by $l$ ) values of 0.288 and 0.289 for $\left(h_{c}\right)_{50}$ for the warm and cold airspaces, respectively. These values, adjusted for departure from $50^{\circ} \mathrm{F}$ mean temperature (using eq (4a), appendix), became 0.282 and 0.302 , respectively. The radiation coefficients, $E h_{r}$, were 0.093 and 0.021 (using fig. 5) for the warm and cold airspaces, respectively. Thus the thermal conductances were calculated to be, for the warm airspace,

$$
\begin{aligned}
& C^{\prime}=0.282+0.093=0.375, \\
& R^{\prime}=2.67,
\end{aligned}
$$

and for the cold airspace,

$$
\begin{aligned}
& C^{\prime}=0.302+0.021=0.323, \\
& R^{\prime}=3.10 .
\end{aligned}
$$

The thermal resistance of a panel space containing a fibrous blanket with tandem adjacent warm and cold airspaces (as in test 117) is the sum of the thermal resistances of the component parts. The thermal resistance of the blanket used in each calculation was the experimentally determined value, in this case 7.32 . 'The calculated resistance of the panel in test 117 was thus

$$
R^{\prime}=2.67+7.32+3.10=13.09 .
$$

The experimental values $(R)$ are compared with the calculated values $\left(R^{\prime}\right)$ by means of the ratio $R / R^{\prime}$, which for this test had values of $0.92,0.85$, and 0.77 for the panel and the warm and cold airspaces respectivcly.

\section{Results and Discussion}

Because of the diversity of materials investigated and of factors affecting the heat transfer, the experimental results are discussed in several sections in two main divisions: (5.1) panels insulated only with aluminum-foil membranes and (5.2) pancls insulated with fibrous insulations in combination with reflective surfaces.

In each of these sections, airspaces are considered that differed in some respects from airspaces of the exemplary, or model, type, on which the data given in the appendix were based. Except for these variables, the construction of the panel and the conditions existing during the measurements were substantially the same as those used in establishing the data on which the calculated resistances are based. Consequently, the differences between the measured and calculated values are in reality the differences between the measured results in two separate experiments, and these differences are the experimentally determined effects of the variable factors, within the precision of the measurements. In each section, when the observed and calculated results differed significantly, a discussion of the differences is presented.

\subsection{Panels Insulated Only With Aluminum- Foil Membranes}

The data in table 2 are for $3 \frac{3}{8}-$ in. panels with two tandem airspaces separated by an aluminumfoil membrane at midspace.

\section{a. Effect of Moisture Condensation}

The results given in part $\mathrm{A}$ of table 2 were obtained with panels 1 and 2 , each of which had a continuous membrane (without holes or perforations) at midspace. Although the observed panel resistance values ranged from about 3.5 to about 12 , depending on the orientation and direction of heat flow, the values of $R / R^{\prime}$ for the panels ranged only from 0.86 to 0.98 . For the cold airspace, the $R / \dot{R}^{\prime}$ values were substantially constant and equal to about 1.03. However, for the warm airspace, the value of $R / R^{\prime}$ varied with the orientation of the panel, ranging from about 0.87 when the panel was vertical and the heat flow was horizontal, 


\begin{tabular}{|c|c|c|c|c|c|c|c|c|c|c|c|c|}
\hline \multirow[b]{2}{*}{ Test } & \multirow[b]{2}{*}{$\begin{array}{l}\text { Direction of heat } \\
\text { flow }\end{array}$} & \multicolumn{5}{|c|}{ Panel } & \multicolumn{3}{|c|}{ Warm airspace ${ }^{a}$} & \multicolumn{3}{|c|}{ Cold airspace } \\
\hline & & $\begin{array}{l}\text { Mean } \\
\text { tempera- } \\
\text { ture }\end{array}$ & \begin{tabular}{c|} 
Temper- \\
ature dif- \\
ference
\end{tabular} & $R$ & $R^{\prime}$ & $R / R^{\prime}$ & $R$ & $R^{\prime}$ & $R / R^{\prime}$ & $E$ & $R^{\prime}$ & $R / R^{\prime}$ \\
\hline
\end{tabular}

A. Panels 1 and 2, without holes in membrane.

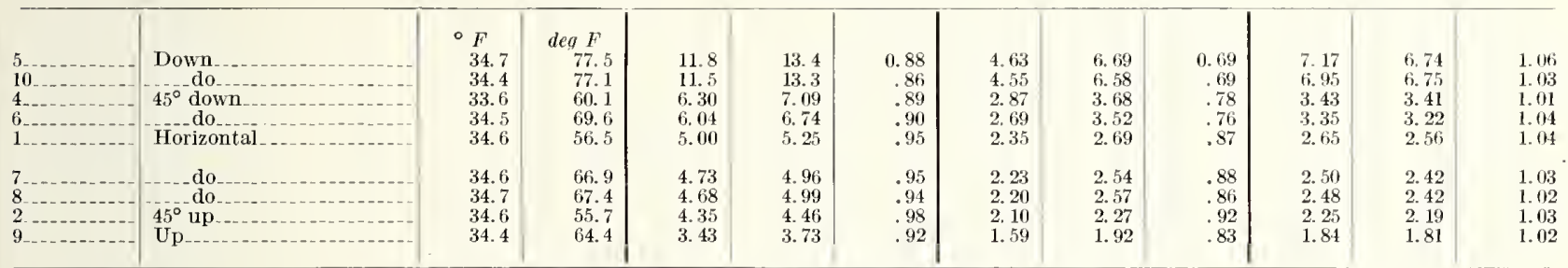

B. Panel 3, with holes in membrane to allow air circulation betwcen spaces b

\begin{tabular}{|c|c|c|c|c|c|c|c|c|c|c|c|c|}
\hline $\begin{array}{l}14 \\
11 \\
13 \\
12\end{array}$ & $\begin{array}{l}\text { Down } \\
\text { Horizontal } \\
45^{\circ} \text { up }\end{array}$ & $\begin{array}{l}34.4 \\
34.5 \\
34.8 \\
34.5\end{array}$ & $\begin{array}{l}79.0 \\
65.5 \\
65.1 \\
65.0\end{array}$ & $\begin{array}{l}13.6 \\
3.99 \\
3.68 \\
3.59\end{array}$ & $\begin{array}{l}13.4 \\
4.95 \\
4.26 \\
3.73\end{array}$ & $\begin{array}{r}1.01 \\
.81 \\
.86 \\
.96\end{array}$ & $\begin{array}{l}6.40 \\
1.97 \\
1.82 \\
1.87\end{array}$ & $\begin{array}{l}6.60 \\
2.53 \\
2.15 \\
1.87\end{array}$ & $\begin{array}{r}0.97 \\
.78 \\
.85 \\
1.00\end{array}$ & $\begin{array}{l}7.19 \\
2.02 \\
1.86 \\
1.72\end{array}$ & $\begin{array}{l}6.83 \\
2.42 \\
2.11 \\
1.86\end{array}$ & $\begin{array}{r}1.05 \\
.84 \\
.88 \\
.92\end{array}$ \\
\hline
\end{tabular}

a For part A, condensed moisture was observed on the membrane on the cold side of this airspace.

b The holes approximated $0.4-\mathrm{in} .{ }^{2} / \mathrm{ft}$, width of panel, and were spaced $56.5 \mathrm{in}$. apart longitudinally.

to 0.69 and 0.83 when the panel was horizontal and the heat flow was down and up, respectively.

The differences betwecn the measured and calculated values of resistance of the panel were entircly due to the differences between the values for the warm airspace. No significant part of these differences can be attributed to uncertainty in the calculated coefficient for combincd convection and conduction. There is good evidence that they were due to impairment of the thermal reflectance of the foil surface on the cold side of the warm airspace, as a result of moisture condensation. At the end of the tests of panels 1 and 2, examination showed that water vapor had condensed and caused visiblc staining of this foil surface near the bottom of the metering section, over about 10 percent of the test area, and moisture was observed on this area when the panels were opened. The other surfacc of the foil was evcrywhere unstained.

There is evidence that a film of water a few thousandths of an inch thick has an emittance, at ordinary temperatures, of 0.9 or greater. On the basis that condensation of moisture on the membrane increased locally the absorption of heat radiated across the warm airspace, it is calculated that the wetting of 4 to 14 percent of the foil arca would account for the decrease of the experimental warm-airspace resistance from the calculated values. The observed stained area of the foil was about 10 percent, in fair agreement with the above estimates.

There is reason to believe that the distribution of condensation on the foil changed with orientation. In the vertical position, the foil was cooler near the bottom, for the same average temperature, than it was in the horizontal positions with upward or downward heat flow, chiefly becausc of the behavior of the convection air currents, and thus condensation would be more likely, and more concentrated, in this orientation. For a horizontal airspace with downward heat flow, moisture on a cool reflective surface would tend to be widely distributed becausc of local heating of wetted areas due to their increased absorptance for radiant energy.

Since the warm faces of the panels werc ncarly perfect vapor barriers, the moisturc on the foil in these tests must have come chiefly from the wood framing. The wood was in approximate moisture equilibrium with the laboratory atmosphcre (average relative humidity about 50 perecnt) when the panels were closed, and within a few hours the panel was subjected to air temperatures of about $75^{\circ} \mathrm{F}$ on the warm side and $-3^{\circ} \mathrm{F}$ on the cold side. Normally, there would be a period of many weeks during which the framing in an actual building could dry slowly before the membrane reached a low temperature at which condensation might occur. Of equal or greater importance in this connection is the fact that in an actual building, unless the construction on the warm side of the airspace were practically impervious to the passagc of vapor, the vapor pressure inside the building would causc permeation of vapor in to the space and continuing condensation on the foil when its temperature was below the dewpoint in the building. The possibility of loss of some of the insulating value of an airspace with a reflective surface on its cold side warrants careful analysis (e. g., by the method given by Woolley ${ }^{3}$ ) of the temperatures of the

${ }^{3}$ H. W. Woolley, Moisture condensation in building walls, NBS Building Materials and Struetures Report BMS63 (1940). 
reflective surface under the conditions of use, unless condensation is prevented by the use in such a position of a reflective membrane of low vapor resistance as compared to that of the construction on the warm side of the membrane.

The stains made by condensation on the foil in a period of about 2 weeks were casily visible, but the emittances of the stained areas after drying were found by measurement to be the same as those of unstained areas of the foil $(0.03)$.

b. Effect of Air Girculation Between Tandem Airspaces Through Holes in the Dividing Aluminum-Foil Membrane

Part B of table 2 gives data for a panel (No. 3) in which the effect of air eirculation through holes in a midspacc aluminum-foil membrane was investigated. The membrane was perforated at each end by a set of three holes, each $0.58 \mathrm{in}$. square as shown in $\mathrm{D}$ of figure 2. The distance between eenters of the two sets of holes was 56.5 in. Each set of holes had a total area of $1 \mathrm{in} .^{2}$, thus approximating an average aperture of $0.4-i n .^{2} /$ it width of panel.

When the panel was horizontal and heat flow was upward or downward, the $R / R^{\prime}$ ratios showed good agreenent between experimental and caleulated resistances for the panel, and for cach of the airspaces. However, when there was a difference of elevation of the two sets of holes, as was the case when heat flow was either horizontal or $45^{\circ}$ upward, the panel and airspace $R / R^{\prime}$ ratios were decreased by roughly 15 percent as a result of air circulation through the holes.

It appear's from these results that the effect of air cireulation through small holes at the ends of a membrane dividing horizontal airspaces was negligible for downward heatflow, and probably small for upward heatflow. However, when the holes had a considerable difference in elevation, there was a reduction of thermal resistance of the airspaces, ranging from 12 to 18 percent for the test conditions (approximately $32 \mathrm{deg} \mathrm{F}$ temperature difference across each air space). These results apply, of course, only for air circulation induced solely by the thermal conditions in the intcreonnected airspaces, and not for air movements induced by extcrnal-pressure differences.

\section{c. Effect of Nonuniformity of Thickness on the Thermal Resistance of Airspaces}

Table 3 gives results obtained in investigating the effect of nonuniformity of thickness of an airspace on its thermal resistance. 'The data were obtained with a $3 \frac{36}{8}$-in. panel having an aluminumfoil membrane installed between framing members in a plane oblique to the plane of the panel, dividing the panel airspaec into two tandem wedge-shaped spaces. The details of the three installations tested are shown in figure 3 (see section $\mathrm{K}$, and circles $\mathrm{T}$ and $U$ ). The three shapes of the wedge-shaped spaces are indicated
TABLE 3. Thermal resistance of tandem wedge-shaped air-

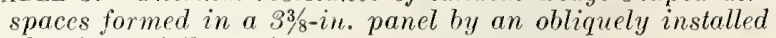
aluminum-foil membrane ${ }^{a}$

Resistanees are expressed in deg $\mathrm{F}$ per (Btu/hr $\left.\mathrm{ft}^{2}\right)$

\begin{tabular}{l|l|l|l|l|l}
\hline \hline 'Test & Direetion of heat flow & \multicolumn{4}{|c}{ Panel } \\
\cline { 2 - 4 } & $\begin{array}{c}\text { Mean } \\
\text { temper- } \\
\text { ature }\end{array}$ & $\begin{array}{c}\text { Temper- } \\
\text { ature dif- } \\
\text { ference }\end{array}$ & $R$ & ${ }^{\circ} R^{\prime}$ & $R / R^{\prime}$ \\
\hline
\end{tabular}

A. Panel 10 (details $\mathrm{K}$ and $\mathrm{T}$ of fig. 3 ), $A=1 / 16 \mathrm{in}$.

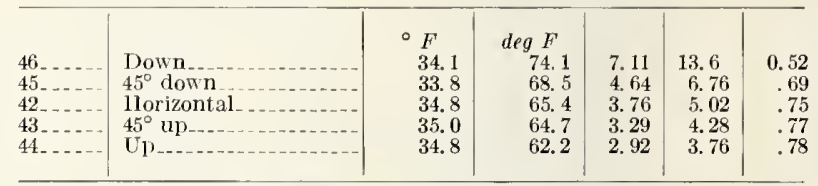

B. Panel 12 (details $\mathrm{K}$ and $\mathrm{U}$ of fig. 3 ), $A=1 / 2 \mathrm{in}$.

\begin{tabular}{|c|c|c|c|c|c|c|}
\hline $\begin{array}{l}59 \ldots \\
58 \ldots \\
55 \ldots \\
56 \ldots \\
57 \ldots \ldots\end{array}$ & $\begin{array}{l}\text { Down } \\
45^{\circ} \text { down } \\
\text { Horizontal } \\
45^{\circ} \text { up } \\
\text { Up }\end{array}$ & $\begin{array}{l}34.6 \\
34.5 \\
35.2 \\
35.2 \\
34.9\end{array}$ & $\begin{array}{l}76.1 \\
69.3 \\
67.4 \\
66.1 \\
63.3\end{array}$ & $\begin{array}{l}8.72 \\
5.19 \\
4.22 \\
3.65 \\
3.18\end{array}$ & $\begin{array}{r}\text { 13. } 5 \\
6.72 \\
4.97 \\
4.24 \\
3.74\end{array}$ & $\begin{array}{r}0.65 \\
.77 \\
.85 \\
.86 \\
.85\end{array}$ \\
\hline
\end{tabular}

C. Panel 15 (details $\mathrm{K}$ and $\mathrm{U}$ of fig. 3 ), $A=1 \mathrm{in}$.

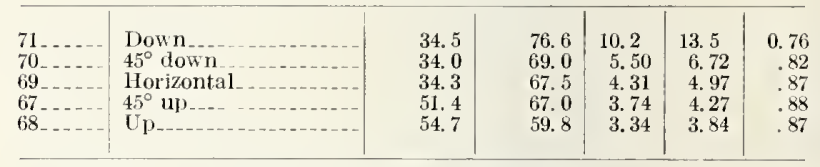

a For each panel, the thickness of each wedge-shaped space is given at its narrow edge by $A$, and at its thiek edge by $\left(3 \frac{3}{8}-A\right)$.

b The resistance $P^{\prime}$ is given for two tandern airspaces, each of uniform $1^{11 / 16-i n . ~ t h i c k n e s s, ~ a n d ~ w i t h ~} E_{t}=E_{c}=0.03$.

by the thickness of each space at its narrowest edge $(A)$, and that at its thickest edge $\left(3 \frac{3}{8}-A\right)$ near the opposite longitudinal framing member. The distance between the framing members was $14 \frac{3}{8}$ in. The values of $R^{\prime}$ in table 3 were based on two tandem airspaces of uniform $111 / 16$-in. thickness, assuming $E_{w}=E_{c}=0.03$.

The results in table 3 show by the $R / R^{\prime}$ ratios that the resistance of the panel decreased as the dimension $A$ decreased (i. e., as the nonuniformity of airspace thickness increascd) for all directions of heatflow. This is also shown in figure 4, in which the average observed thermal resistancc per space is plotted versus the space thicknesses at the narrow and thick edges. The points plotted at an edge thickness equal to $1^{11 / 16}$ in. give the value of $R^{\prime}$ for a space of uniform thickness equal to half that of the pancl space.

Figure 4 shows further that the effect of nonuniformity of thickness increased, in both absolute and relative reductions of resistance, as the thermal resistance, $R^{\prime}$, for a uniform airspace increased in accordance with orientation and direction of heatflow. The wedge shape of these spaces caused a lateral temperature gradient in the foil membrane, which promoted greatcr convection in each airspace than would have existed in a uniform airspace with little lateral tempcrature gradient in the foil. Since the thermal resistance of an airspace with highly reflective surfaces chicfly depends on the convective activity in the 


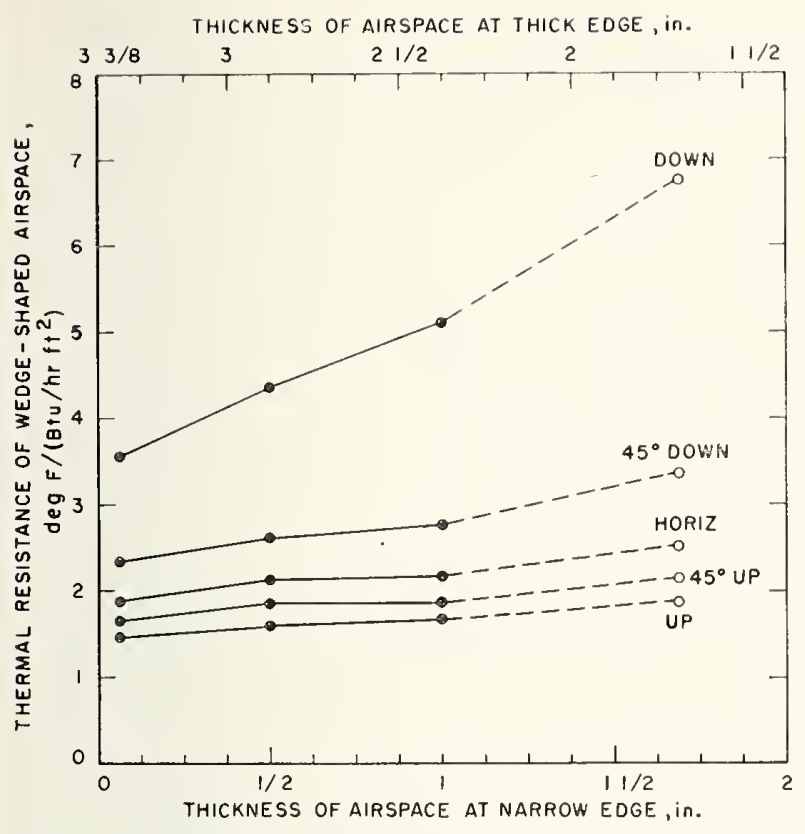

FIGURE 4. Average thermal resistance of a wedge-shaped airspace 143/8 in. wide, versus thicknesses at edges, for five directions of heat flow.

- observed; $O$, calculated for a space of uniform 113/6-in. thickness with $E_{w}=E_{c}=0.013$.

space, those spaces in which convection is normally small (i. e., those of high resistance, such as horizontal spaces with heatflow downward) are most affected by the augmentation of convection due to nonuniform temperatures at a boundary of the airspace.

It is evident that uniformity of airspace thickness and surface temperatures is of major importance in realizing maximal thermal resistance for horizontal airspaces with heatflow downward, but is of much less importance for the same application with heatflow upward, or for other orientations.

d. Effect of Minute Perforations in a Foil Membrane Forming Tandem Airspaces, and Some Results Indicating An Effect Due to Radiation From the Wood Framing

The results in table 4 are for two tandem 3.8-in. airspaces formed in a $75 / 8$-in. panel by means of a membrane at midspace of the panel.

For part $A$, the membrane was a specially prepared $0.001-$ in. aluminum foil perforated with 64 minute holes per square inch. The objective was to determine the effect of the perforations.

With a perforated highly reflective membrane at midspace, therc is, in addition to the heat transfer across each airspace with an unperforated membrane, a further heat transfer due to radiation from the warm face of the panel through the apertures to the cold face. In effect, this is a transfer of heat between the highly cmissive panel faces in parallel with the normal transfer calculated by the procedure given in the appendix, because the radiant cnergy entering an aperture in the membrane is almost wholly absorbed by the cold-side face of the panel beyond, due to its high absorptance and the high reflectance of the foil membrane on the warm side of the cold airspace. The fraction of the incident radiant energy that passes through the apertures and is absorbed by the cold face of the panel is therefore approximately equal to $a$, the fraction of the membrane area represented by the apertures, if $a$ is small. The corresponding heat transfer, per square foot of panel area, is equal to $\theta\left(a h_{\tau}\right)$, where $\theta$ is the temperature difference from face to face of the pancl, and $h_{r}$ is the linear coefficient for radiation (see eq (2), appendix) at the mean of the temperatures of the panel faces.

The total calculated heat transfer per square foot of panel $\left(q^{\prime}\right)$ is closely the sum of the above quantity and that calculated by using the method given in the appentix, $\mathrm{Or}^{\circ}$

$$
q^{\prime}=\theta\left(a h_{r}\right)+\frac{\theta}{2 R^{\prime}},
$$

where $R^{\prime}$ is the average of the individual calculated thermal resistances of the two airspaces.

The expcrimental panel resistance, $R$, is computed as $\theta / q$, where $q$ is the observed heatflow rate per square foot of panel. Conforming to this, the calculated panel resistance, $R_{p}^{\prime}$, is given, with the airl of the equation above, by

$$
R_{p}^{\prime}=\frac{\theta}{q^{\prime}}=\frac{2 R^{\prime}}{1+2 R^{\prime} a h_{r}}=\frac{2}{1 / R^{\prime}+2 a h_{r}} .
$$

The denominator of the last fraction is equivalcnt to $C^{\prime}+2 a h_{\tau}$ ), or approximatcly, using eq (1) of the appendix, to $h_{c}+(E+2 a) h_{\tau}$, where $h_{c}$ and $h_{\tau}$ are average values for the two airspaces. Thus, in effect, the perforations increase the ordinary radiation interchange factor, $E$, for each airspace (see eq (3), appenclix) by an amount approximatcly equal to $2 a$, for the case of tandem airspaces made reflective by an intermediate perforated highly reflective membrane.

The perforations in the foil membrane of part A were made in eflect with a punch against a rosilient backing. Microscopic examination showed that indentations were formed, about $0.025 \mathrm{in}$. sq at the top, tapering to ruptures or tears at the bottom, yielding apertures of irregular shape. Measurements on perforations indicated that the area of the apertures, viewed perpendicular to the membrane, ranged from about 24 to 56 percent of the indented area. Assuming an average value of 40 percent, it was estimated that the area of apertures in the membrane was approximately 1.6 percent of the membrane area.

For the membrane of part $A, E$ was taken as equal to the value ascertained for bright foil $(0.03)$, 
TABLE 4. Thermal resistance of a $75 / 8-i n$. panel with a perforated or nonperforated membrane in midspace

Rgsistances are expressed in deg $\mathrm{F}$ per (Btu/hr ft ${ }^{2}$ )

\begin{tabular}{|c|c|c|c|c|c|c|c|c|c|c|c|c|}
\hline \multirow[b]{2}{*}{ Test } & \multirow[b]{2}{*}{$\begin{array}{l}\text { Direction of heat } \\
\text { flow }\end{array}$} & \multicolumn{5}{|c|}{ Panel } & \multicolumn{3}{|c|}{ Warm airspace } & \multicolumn{3}{|c|}{ Cold airspace } \\
\hline & & $\begin{array}{c}\text { Mcan } \\
\text { tempera- } \\
\text { ture }\end{array}$ & $\begin{array}{l}\text { Temper- } \\
\text { atirc dif- } \\
\text { fcrence }\end{array}$ & $R$ & $R^{\prime}$ & $R / R^{\prime}$ & $R$ & $R^{\prime}$ & $R / R^{\prime}$ & $R$ & $R^{\prime}$ & $R / R^{\prime}$ \\
\hline \multicolumn{13}{|c|}{ A. Panel 16 , perforated foil membrane ( $\left.E_{w}=E_{c}=0.062 \mathrm{virtual}\right)$} \\
\hline $\begin{array}{l}74 \\
73 \\
72 \\
75 \\
76 \\
76\end{array}$ & $\begin{array}{l}\text { Down } \\
45^{\circ} \text { down } \\
\text { Horizontal } \\
45^{\circ} \text { lip } \\
\text { Up }\end{array}$ & $\begin{array}{c}\circ F \\
35.0 \\
35.1 \\
34.4 \\
34.6 \\
34.2\end{array}$ & $\begin{array}{r}\operatorname{deg} F \\
82.2 \\
70.7 \\
67.3 \\
66.8 \\
65.2\end{array}$ & $\begin{array}{r}\text { 15. } 0 \\
6.10 \\
4.65 \\
\text { 4. } 01 \\
3.61\end{array}$ & $\begin{array}{c}15.5 \\
6.26 \\
4.89 \\
4.18 \\
3.90\end{array}$ & $\begin{array}{l}0.97 \\
.97 \\
.95 \\
.96 \\
.93\end{array}$ & 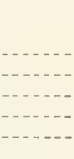 & $\begin{array}{l}7.34 \\
3.12 \\
2.45 \\
2.10 \\
1.96\end{array}$ & & & $\begin{array}{l}8.11 \\
3.14 \\
2.44 \\
2.08 \\
1.94\end{array}$ & \\
\hline \multicolumn{13}{|c|}{ B. Panel 21, nonperforated foil membranc ( $E_{w}=E_{c}=0.03$ ) } \\
\hline $\begin{array}{l}103 \\
104 \\
105 \\
106 \\
107\end{array}$ & $\begin{array}{l}\text { Down } \\
45^{\circ} \text { down } \\
\text { Horizontal } \\
45^{\circ} \text { up } \\
\text { Up }\end{array}$ & $\begin{array}{l}34.8 \\
35.2 \\
35.5 \\
36.0 \\
35.7\end{array}$ & \begin{tabular}{l|}
82.4 \\
71.2 \\
68.7 \\
67.3 \\
66.2
\end{tabular} & $\begin{array}{c}14.9 \\
5.91 \\
4.62 \\
3.94 \\
3.59\end{array}$ & $\begin{array}{l}19.4 \\
6.84 \\
5.21 \\
4.42 \\
4.10\end{array}$ & $\begin{array}{r}0.77 \\
.86 \\
.89 \\
.89 \\
.88\end{array}$ & $\cdots$ & $\begin{array}{l}\text { 9. } 43 \\
\text { 3. } 44 \\
2.63 \\
\text { 2. } 23 \\
\text { 2. } 07\end{array}$ & & & $\begin{array}{l}10.0 \\
3.40 \\
2.58 \\
2.19 \\
2.03\end{array}$ & $\begin{array}{ll}-- \\
-- \\
--\end{array}$ \\
\hline \multicolumn{13}{|c|}{ C. Panel 21, nonpcrforated foil membrane $\left(E_{\varkappa}=E_{c}=0.03\right)$} \\
\hline $\begin{array}{l}109 \\
110 \\
111 \ldots \\
112 \\
113 \\
-.-\end{array}$ & $\begin{array}{l}\text { Down } \\
45^{\circ} \text { down } \\
\text { Horizontal } \\
45^{\circ} \text { up } \\
\text { Up }\end{array}$ & \begin{tabular}{l|}
66.4 \\
66.2 \\
64.3 \\
63.6 \\
63.4
\end{tabular} & $\begin{array}{l}133.2 \\
117.7 \\
109.2 \\
106.2 \\
103.2\end{array}$ & $\begin{array}{l}9.64 \\
4.48 \\
3.80 \\
3.40 \\
3.08\end{array}$ & $\begin{array}{l}17.7 \\
5.98 \\
4.67 \\
3.96 \\
3.71\end{array}$ & $\begin{array}{r}0.54 \\
.75 \\
.81 \\
.86 \\
.83\end{array}$ & - & $\begin{array}{l}\text { 8. } 82 \\
\text { 3. } 03 \\
2.37 \\
2.01 \\
1.89\end{array}$ & & & $\begin{array}{l}8.83 \\
2.95 \\
2.30 \\
1.95 \\
1.82\end{array}$ & \\
\hline \multicolumn{13}{|c|}{ D. Panel 29, perforated foil-kraft paper laminatc a $\left(E_{w}=E_{c}=0.03\right)$} \\
\hline $\begin{array}{l}151 \\
152 \\
153 \\
154 \mathrm{~b}\end{array}$ & $\begin{array}{l}\text { Down } \\
\text { Horizontal } \\
\text { Up } \\
\text { Horizontal }\end{array}$ & \begin{tabular}{l|}
49.2 \\
50.4 \\
46.3 \\
49.6
\end{tabular} & $\begin{array}{r}102.3 \\
84.9 \\
75.8 \\
86.4\end{array}$ & \begin{tabular}{r|}
14.4 \\
4. 50 \\
3.70 \\
4.55
\end{tabular} & $\begin{array}{r}18.3 \\
5.04 \\
3.96 \\
4.97\end{array}$ & $\begin{array}{r}0.79 \\
.89 \\
.93 \\
.92\end{array}$ & $\begin{array}{l}6.21 \\
2.24 \\
1.74\end{array}$ & $\begin{array}{l}9.21 \\
\text { 2. } 57 \\
\text { 2. } 03 \\
\text { 2. } 51\end{array}$ & $\begin{array}{r}0.67 \\
.87 \\
.86\end{array}$ & $\begin{array}{l}8.20 \\
2.20 \\
1.96\end{array}$ & $\begin{array}{l}9.12 \\
2.47 \\
1.93 \\
2.46\end{array}$ & $\begin{array}{r}0.90 \\
.91 \\
1.02\end{array}$ \\
\hline
\end{tabular}

a Kraft-paper side faced warm airspace, and foil side faced cold airspace. Warm side of warm airspace was surfaced with aluminum foil.

b Duplicate of test 152; no thermocouples on membrane.

and $a$ was approximately 0.016 ; thus, the virtual radiation interchange factor for each of the airspaces was about 0.062 . The values of $R^{\prime}$ in part $A$, for each space and for the panel, were calculated by using this value of the factor.

Measurements of the cmittance of the perforated foil membrane were also made with a radiometer. For similar unperforated foil, an emittance of 0.028 was obtained; for the perforated foil, the emittance was 0.034 when it was applied to a convex tarnished brass surface, and 0.040 when the brass was painted to have a measured emittance of 0.94 . For the last observation, the measured emittance $(0.040)$ should be equal to $0.028(1-a)+0.94 a$, whence $a$ is calculated as equal to 0.013 . This is consistent with the estimate obtained from the microscopic examination.

The values of $R / R^{\prime}$ for the pancl in part $A$ approximate 0.96 . Since the membrane temperature was not measured in these tests, values of $R$ for each space could not be determined. The reduction in panel resistance due to the increase of $E_{w}$ and $E_{c}$ for panel 16 from a value of 0.03 to a value of 0.062 as a result of radiation through the membrane perforations is indicated by comparison of corresponding values of $R^{\prime}$ for panels 16 and 21 .

Air circulation through the perforations of the membrane appears to have had little effect on resistance, even though the perforated area totaled about 27 in. $^{2}$ in the 1,678 in. $^{2}$ of membrane in the test areas of the panel. If it occurred, its effect would be greatest when the panel was vertical (test 72) and least when the panel was horizontal and heatflow was downward (test 74), as shown by the results in part $B$ of table 2 . The corresponding $R / R^{\prime}$ ratios for the panel were 0.95 and 0.97 , respectively, indicating that there was substantially no air circulation effect, within the precision of the results.

The tests in part B of table 4 were made with an unperforated foil membrane in the same panel frame for comparison with the perforated membrane. The values of $R$ for the panel in part $\mathrm{B}$ agreed with the corresponding values in part $A$ within about 1 percent. Because there were no perforations in the membrane of part $B$, and because the test temperatures were so closely matched as to obviate differences in convection from that cause, the close agreement of the results of parts $A$ and $B$ suggested that some additional heat transfer occurred in the tests of part $B$. Upon analysis, it was found that the values of $R^{\prime}$ for the panel in part B would agree substantially with the observed values of $R$ for all the directions of heat flow, if $E_{20}$ had values between 0.13 and 0.17 , instead of 0.03 , as assumed in calculating the values of $R^{\prime}$ in part $B$. When new values of $R^{\prime}$ for part $\mathrm{B}$ were calculated on the 
assumption that $E_{w}=0.15$ and $E_{c}=0.03$, the values of the ratio $R / R^{\prime}$ in part $\mathrm{B}$ became, in order, 1.04 , $1.00,1.00,0.99,0.97$. The fact that this one assumption holds reasonably well for all five directions of heatflow makes it appear that the reflectance of the foil on the cold side of the warm airspace was reduced by condensation (as in the tests of part $\mathrm{A}$ of table 2).

The tests in part $\mathrm{C}$ of table 4 were made with the same panel and membrane as those of part B, but with considerably increased warm-side temperatures and panel temperature differences. The values of observed panel resistance were decreased more than would be expected for the greater temperature differences and mean temperatures, especially for the case of downward heat flow when the panel was horizontal. Analysis of the results of part $\mathrm{C}$ along the lines used for part $\mathrm{B}$ indicates inferred values of $E_{2}$ between 0.2 and 0.3 for all of the tests except that for downward heat flow. In the latter case, the inferred value of $E_{w}$ is about 0.8 , corresponding to a reduction of the reflectance of the foil facing the warm airspace to a value of about 0.1 . It is probable that due to the higher warm-side temperatures used in these tests, condensation on the foil surface was greater in the tests of part $C$ than in those of part B. Unfortunately, membrane temperatures were not measured in tests 103 to 113 , and consequently comparisons of warm and cold airspace performance could not be made to examine the hypothesis of condensation on the reflective surface of the warm airspace.

Examination of the foil membrane after test 113 showed no evidence of staining, although staples at the bottom of the test area had rusted considerably, showing that moisture had been present. The absence of staining is not conclusive, because foil known to have experienced condensation has later been found to be unmarked by it.

The panel of part D of table 4 was prepared in order to conduct some tests with a midspace membrane and with thick reflective airspaces without effects due to condensation on the reflective surfaces. The membrane was a laminate of kraft paper with 0.00035 -in. aluminum foil on the side facing the cold airspace. The warm airspace was made reflective by means of perforated aluminum foil cemented to the inner surface of the warm face of the panel. The laminated membrane was perforated with 64 holes per square inch; microscopic examination indicated the actual apertures in the foil totaled 0.1 to 0.2 percent of the area, and that in the majority of cases the kraft-paper backing was not actually perforated. Condensation could not materially affect the value of the radiation interchange factor, $E$, for each space, because this was controlled by the low emittance of the reflective warm side of each space.

The values of $R / R^{\prime}$ in part $\mathrm{D}$, for panel 29 , and for each airspace, especially the warmer space, are enough lower than unity to warrant further consideration. Test 154 , which was a repeat of test 152 with a new membrane installed, confirmed the approximate reproducibility of the results with this panel. Further, the values of $R / R^{\prime}$ in part $\mathrm{D}$ are in general lower than those for panel 16 in part $A$, which had the same geometry and which also could not have been subject to condensation on the reflective surfaces.

A possible explanation is that the impaired performance of panel 29 was due to radiation from the sides of the framing members. In both panels, the area of wood framing members exposed to each test airspace was about $3.8 \mathrm{ft}^{2}$, and the membrane area was about $5.8 \mathrm{ft}^{2}$; the emittance of the wood framing was on the order of 0.9 . In the case of panel 29, radiation from the wood framing would be largely absorbed by the highly absorptive kraft surface of the membrane on the cold side of the warm airspace; in panel 16, the membrane surface was highly reflective, and little of the incident radiant energy would be absorbed. Thus, other things being the same, the resistance of the warm airspace of panel 29 would be less than that of panel 16 because of absorption of the radiation from the framing. The cold airspaces of both panels were alike in this regard, but consideration of probable temperature gradients in the wood framing indicates that the effect would be materially reduced in the colder of two tandem airspaces, as the results in part $\mathrm{D}$ also indicate. Assuming that it was responsible for the difference between the calculated and observed resistances of the warm airspace in test 151 , the effect was evaluated from those results and applied as a correction to the calculated resistances for tests 152 and 153 , which then agreed within a small percentage with the observed values for these tests.

The results of the tests in part $\mathrm{D}$ thus possibly indicate that radiation from framing may appreciably reduce the thermal resistance of a thick reflective airspace when the colder side of the airspace is not the reflective surface. It was not feasible to investigate this effect further experimentally in this program, although it may have a bearing upon the most effective use of reflective surfaces in airspaces of considerable thickness. It is probable that the effect would be at least proportionately less for airspaces of lesser thickness.

\subsection{Panels Insulated With Fibrous Insulations in Combination With Reflective Surfaces}

\section{a. Semirigid Mineral-Wool Board Insulation Without and With Reflective Surfaces}

The data of table 5 are for a test panel containing a semirigid mineral-wool-board insulation, $1 \frac{1}{2} \mathrm{in}$. thick, installed to form a 2 -in. warm airspace and a 4-in. cold airspace. The board had a density of about $9 \mathrm{lb} / \mathrm{ft}^{3}$, and had a thermal conductivity of $0.241 \mathrm{Btu} / \mathrm{hr} \mathrm{ft}{ }^{2}\left(\mathrm{deg} \mathrm{F} / \mathrm{min}\right.$.) at $55.8^{\circ} \mathrm{F}$ and of 0.249 at $72.8^{\circ} \mathrm{F}$ as measured by the guarded hotplate method (ASTM C177-45). The hotplate 
TABLE 5. Thermal resistance of a $75 \%$-in. panel with a 11/2-in. semirigid mineral-wool-board insulation in approximate midspace without and with reflective aluminum-foil surfaces

Resistances are expressed in deg $\mathrm{F}$ per (Btu/hr it $\left.{ }^{2}\right)$

\begin{tabular}{|c|c|c|c|c|c|c|c|c|c|c|c|c|c|}
\hline \multirow{2}{*}{ Test } & \multirow{2}{*}{$\begin{array}{l}\text { Direction of } \\
\text { heat flow }\end{array}$} & \multicolumn{5}{|c|}{ Panel } & \multicolumn{3}{|c|}{$\begin{array}{c}\text { Warm airspace, } \\
2 \text { in. }\end{array}$} & \multicolumn{3}{|c|}{$\begin{array}{c}\text { Cold airspace, } \\
4 \text { in. }\end{array}$} & \multirow{2}{*}{$\begin{array}{c}\text { Board } \\
1.5 \mathrm{in} . \\
R\end{array}$} \\
\hline & & $\begin{array}{l}\text { Mean } \\
\text { tenpera- } \\
\text { ture }\end{array}$ & $\begin{array}{c}\text { Temper- } \\
\text { ature } \\
\text { difference }\end{array}$ & $R$ & $R^{\prime}$ & $R / R^{\prime}$ & $R$ & $R^{\prime}$ & $R / R^{\prime}$ & $R$ & $R^{\prime}$ & $R / R^{\prime}$ & \\
\hline
\end{tabular}

A. Pancl 17, board installed as received $\left(E_{w}=E_{e}=0.82\right.$ estimated $)$

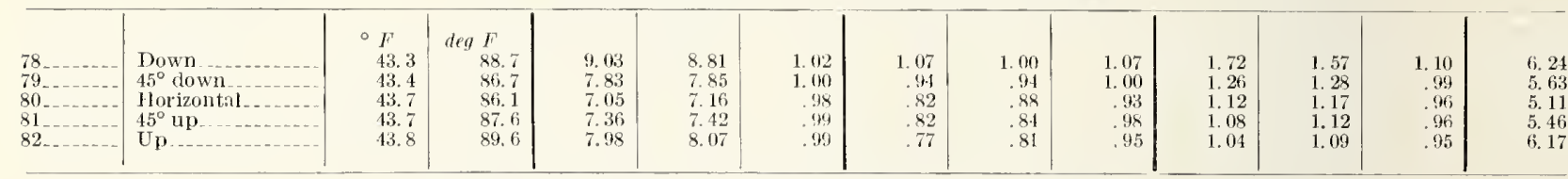

13. Panel 18 , both stufaces of board painted white $\left(E_{w}=E_{c}=0.82\right.$ estimated)

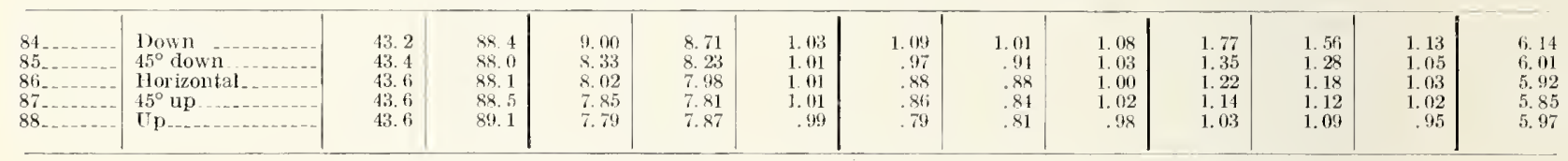

C. Panel 19, aluminum foil cemented on board, warm surface only ( $E_{20}=0.03 ; E_{c}=0.82$ estimated)

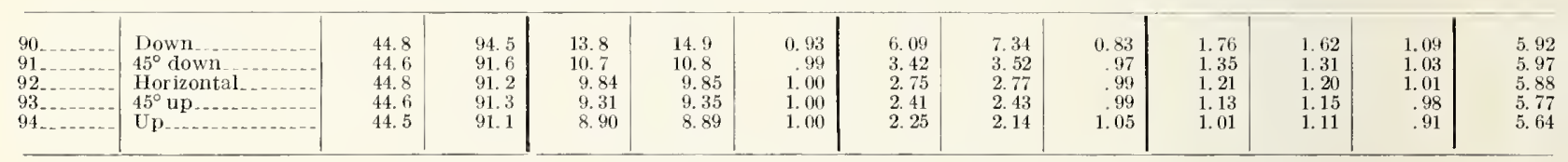

D. Panel 20, aluminum foil cemented on board, both surfaces $\left(E_{w}=E_{c}=0.03\right.$ )

\begin{tabular}{|c|c|c|c|c|c|c|c|c|c|c|c|c|c|}
\hline $96 \ldots$ & Down & 44.4 & 97.4 & 21.0 & 22.7 & 0. 93 & 6. 10 & 7. 50 & 0.81 & 9. 66 & 9.95 & 0.97 & 5. 24 \\
\hline 101 . & $45^{\circ}$ down. & 43.1 & 92.7 & 12.8 & 13.2 & .97 & 3. 52 & 3. 71 & .95 & 3. 56 & 3.71 & .96 & 5. 76 \\
\hline 98 & Horizontal. & 43.5 & 91.4 & 11.4 & 11.5 & .99 & 2.80 & 2.88 & 97 & 2.86 & 2.89 & .99 & 5. 71 \\
\hline & $45^{\circ}$ up & 42.8 & 91.3 & 10.7 & 10. 7 & 1.00 & 2.51 & 2. 50 & 1.00 & 2. 44 & 2.52 & .97 & 5.71 \\
\hline $100_{\ldots} \ldots$ & Up & 42.7 & 91.4 & 9.88 & 9.93 & .99 & 2.31 & 2. 21 & 1.04 & 2.17 & 2.32 & .94 & 5. 40 \\
\hline
\end{tabular}

data indicate that at a mean temperature of $45^{\circ} \mathrm{F}$, which was approximately the mean temperature of the board in the panel tests, the conductivity was 0.236 , equivalent to a thermal resistance for the board of $6.36 \mathrm{deg} F$ per (Btu/hr $\mathrm{ft}^{2}$ ).

Measurements were made on the panel with (a) the surfaces of the board in the as-received condition, (b) both surfaces painted with a flat white paint of 0.9 emittance to inhibit air permeation through the board, (c) aluminum foil of 0.03 emittance cemented to the warm surface of the painted board, and (d) aluminum foil of 0.03 emittance cemented to both surfaces.

Table 5 presents the values of $R, R^{\prime}$, and $R / R^{\prime}$ for the panel and each of the airspaces, and $R$ for the board.

The values of $R$ for the board in part $A$ of the table show a variation with direction of heat flow, the smallest value being obtained with horizontal heat flow when the difference of elevation of the ends of the test airspace was greatest. The obvious explanation is that the effective resistance of the board was decreased by air circulating between the two airspaces through the board as a result of the unequal weights of unit columns of air in the two spaces. The greater uniformity of $R$ for the board in part $B$, for the several directions of heat flow, indicates that air penetration was substantially arrested by the two paint films.

The average value of $R$ for the unpainted board obtained in the hotbox panel tests under conditions in which air circulation through the board was minimal (6.21 for the two horizontal orientations) agreed within about 2 percent with the value (6.36) obtained from the lotplate tests. The average value of $R$ for the painted board in part $B$ (5.98) was slightly less than the average value for the horizontal orientations in part A (6.21) corresponding to conditions of little or no air cirenlation. The decrease is attributed to paint filling the voids between fibers of the board to a depth of $1 / 32$ to $1 / 16 \mathrm{in}$. The values of resistance of the board were substantially independent of the direction of heat flow in parts $B$ and $C$, and in part $D$ for directions of heat flow other than vertically upward or downward. In the latter case, the resistance was unaccountably about 8 percent lower.

Because of the nature of the board, it was not feasible to measure the emittance of its surfaces either before or after painting. For both cases the surface emittances were taken to be 0.9 , yielding an estimated value of 0.82 for the radiation interchange factor, $E$, of the airspaces for calculating 
$R^{\prime}$. For the spaces made reflective by aluminum foil cemented to the board, the value of $E$ was 0.03 , as determined from measurements made on the foil used to surface the board.

Considering the results in parts B, C, and D for the individual airspaces, the average of the $R / R^{\prime}$ ratios for the 30 cases was 0.99 , the extremes being 0.83 and 1.13 . For the 15 cases where the airspace was not highly reflective, the average of the $R / R^{\prime}$ ratios was 1.02 ; for the 15 highly reflective spaces it was 0.96 . The major departures of the $R / R^{\prime}$ ratio from unity occurred in the cases of downward and upward heat flow, chiefly the former. Comparing the test results dircetly, the observed resistances for the nonreflective cold airspace in part $\mathrm{C}$ agree well with the corresponding values in part B; similarly, those for the reflective warm airspace in part $D$ agree well with the values in part $C$.

For the panel, the $R / R^{\prime}$ ratios averaged 0.99 , with extremes of 0.93 and 1.03 . Because the observed resistance of the board in each test had to be used in calculating $R^{\prime}$ for the panel, the $R / R^{\prime}$ ratio should be expected to be nearly unity when the airspaces were not highly reflective and therefore contributed only a small fraction of the total resistance of the pancl installation. In parts C and $\mathrm{D}$, the one or two reflective spaces added much to the panel resistance, and even in these cases the agreement of the observed and calculated panel resistances was good.

Comparison of corresponding observed resistances $R$ for the panel in parts $\mathrm{B}, \mathrm{C}$, and $\mathrm{D}$ of table 5 shows the very substantial increases in insulating effect that resulted when the airspaces adjoining the fibrous insulation were made highly reflective, especially for heat-flow directions other than vertically upward.

The results of the work with this panel are considered to show that the over-all and component resistances for tandem installations of fibrous insulation and reflective or nonreflective airspaces can be calculated with adequate average reliability (i. e., to within less than 10 percent, and considerably better in most cases), if the fibrous insulation and the airspaces are of uniform thickness, and the airspaces are sealed.

b. Flexible Lightweight $11 / 4$-in. Mineral-Wool Blanket With Aluminum-Foil Membrane on Warm SideFour Methods of Installation

Table 6 presents data for four installations in a 33/s-in. panel of a commercial flexible-blanket insulation consisting of $1 \frac{1}{4} \mathrm{~m}$. of $0.6 \mathrm{lb} / \mathrm{ft}^{3}$ density mineral wool faced on one side with $0.001-\mathrm{in}$. aluminum foil. As measured in the guarded hotplate (ASTM C177-45) with the blanket compressed to a thickness of 1 in., the thermal conductivity of the fibrous material was $0.277 \mathrm{Btu} / \mathrm{hr} \mathrm{ft}^{2}(\mathrm{deg} \mathrm{F} / \mathrm{in}$.) at $74^{\circ} \mathrm{F}$ mean temperature. On the basis of a thickness of $1 \frac{11}{4} \mathrm{in}$., this yields an estimated thermal resistance of $4.8 \mathrm{deg}$ F per (Btu/hr ft ${ }^{2}$ ) for the blanket at its approximate mean temperature $\left(30^{\circ} \mathrm{F}\right)$ in the panel tests.
Measurements were made with the insulation installed in the panel in four different ways considered to be of practical interest, as indicated in table 6 .

The panel resistances, $R$, in table 6 show that the greatest insulating value, for all directions of heat flow, was obtained with the midspace installation $A$; installation $B$ with the blanket bowed into the space from the warm side was next in effectiveness. Installations $C$ and $D$ gave approximately similar results, except when heat flow was downward. D is considered a less desirable method of installation from the standpoint of possible moisture condensation on the aluminum-foil vapor barrier, bccause the foil temperature under the framing must approach that of the sheathing applied to the framing.

The blanket resistances were maximal for installation $A$, in which the fibrous material was uncompressed, and were minimal for installation D, in which the fibrous material, in addition to being compressed near the framing members as in B and $C$, was further restrained from its full expansion even near the center of the space by the tautness of the foil facing. The resistance of the blanket in installation A for downward heat flow (4.62) agrees within 4 pereent with the value (4.8) inferred from the hotplate test.

For a blanket of approximate convex-lens shape (i. e., thicker at the middle than at the edges), the average thermal resistance, over all its area, is less than the apparent resistance obtained when the temperature diop through the blanket, as determined with thermocouples attached to its faces at points midway between the longitudinal framing members (see fig. 2, arrangement $\mathrm{E}$ ), is divided by the average observed rate of heat flow per square foot of blanket. Thus, the tabulated values of apparent blanket resistance, which were obtained in this way, tend to be a little greater than the actual average or effective resistance of the blanket in the case of installations B, C, and D (especially B and D), in which a convex-lens shape for the fibrous material was most marked. Accordingly, since the $R^{\prime}$ values for the pancls were based on the tabulated values of the blanket resistance, which are greater than the effective values, the $R / R^{\prime}$ ratios for the panels are necessarily less than unity in these cases. For installations C and D, this effect was somewhat offset by the small observed thermal resistances at the contact between the blanket and the warm and cold faces, respectively, of the panel, which were not allowed for in calculating $R^{\prime}$.

Considering the $R / R^{\prime}$ ratios, installation A developed from 88 to 97 percent of the calculated panel insulating value. The departures are chiefly due to the departures from unity of the $R / R^{\prime}$ ratio for the reflective warm airspace, which nevertheless contributed very substantially to the insulating value of the pancl. Installation B, with the blanket bowed into the panel space, developed about 80 percent of the thermal resistance calcu- 


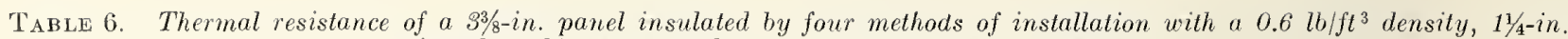
mineral-wool blanket faced on warm surface with aluminum foil

Resistances are cxpcessed in dcg $\mathbf{F}$ per (Btu/hr $\mathrm{ft}^{2}$ )

\begin{tabular}{|c|c|c|c|c|c|c|c|c|c|c|c|c|c|}
\hline \multirow{2}{*}{ Test } & \multirow{2}{*}{$\begin{array}{l}\text { Direction of } \\
\text { heat flow }\end{array}$} & \multicolumn{5}{|c|}{ Panel } & \multicolumn{3}{|c|}{ Warm airspaee } & \multicolumn{3}{|c|}{ Cold airspace } & \multirow{2}{*}{ Blanket } \\
\hline & & $\begin{array}{c}\text { Mean } \\
\text { tempera- } \\
\text { ture }\end{array}$ & $\begin{array}{c}\text { Tempe:- } \\
\text { ature } \\
\text { diffcrenee }\end{array}$ & $R$ & $R^{\prime}$ & $R / R^{\prime}$ & $R$ & $R^{\prime}$ & $R / R^{\prime}$ & $R$ & $R^{\prime}$ & $R / R^{\prime}$ & \\
\hline
\end{tabular}

A. Panel 8, fibrous blanket installed at midspace with no compression $\left(E_{w}=0.03, E_{c}=0.82\right.$ estimated)

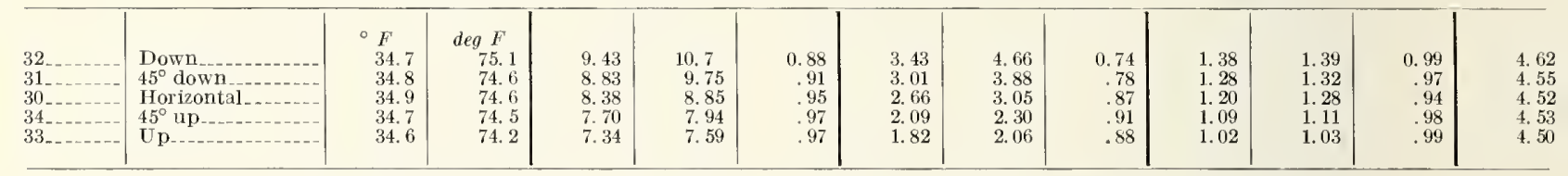

B. Panel 4, installcd over warm side of studs and pushed halfway into stud spaec $\left(\boldsymbol{E}_{w}=0.03 ; E_{e}=0.82\right.$ estimated $)$

\begin{tabular}{|c|c|c|c|c|c|c|c|c|c|c|c|c|c|}
\hline $\begin{array}{l}19 \\
16 \\
18 \\
17 \\
18 \ldots\end{array}$ & $\begin{array}{l}\text { Down } \\
\text { Horizonal } \\
45^{\circ} \text { up } \\
\text { Up }\end{array}$ & $\begin{array}{l}34.8 \\
34.7 \\
34.8 \\
34.6\end{array}$ & $\begin{array}{l}75.6 \\
73.6 \\
73.8 \\
74.2\end{array}$ & $\begin{array}{l}8.64 \\
6.83 \\
6.50 \\
6.21\end{array}$ & $\begin{array}{l}10.4 \\
8.70 \\
7.84 \\
7.51\end{array}$ & $\begin{array}{r}0.83 \\
.79 \\
.83 \\
.83\end{array}$ & $\begin{array}{l}3.75 \\
2.00 \\
1.62 \\
1.35\end{array}$ & $\begin{array}{l}4.65 \\
3.16 \\
2.37 \\
2.13\end{array}$ & $\begin{array}{r}0.81 \\
.63 \\
.68 \\
.63\end{array}$ & $\begin{array}{r}0.53 \\
.61 \\
.61 \\
.57\end{array}$ & $\begin{array}{l}\text { 1. } 42 \\
1.32 \\
1.20 \\
1.09\end{array}$ & $\begin{array}{r}0.37 \\
.46 \\
.51 \\
.52\end{array}$ & $\begin{array}{l}\text { 4. } 37 \\
\text { 4. } 22 \\
\text { 4. } 27 \\
\text { 4. } 29\end{array}$ \\
\hline
\end{tabular}

C. Pancl 5, installed tautly over warm side of studs with foil against warm surfaee plate $\left(\boldsymbol{E}_{c}=0.82\right.$ estimated)

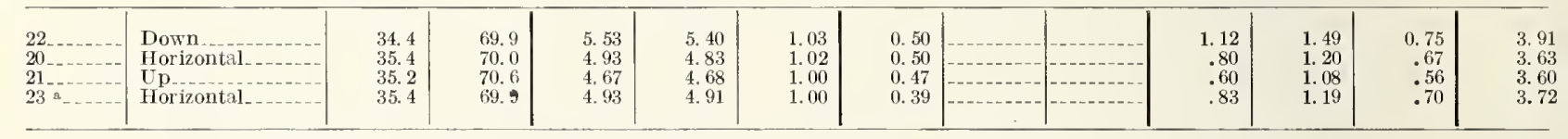

D. Panel 7, installed over cold side of studs and compressed with blanket against cold surface plate $\left(E_{w}=0.03\right)$

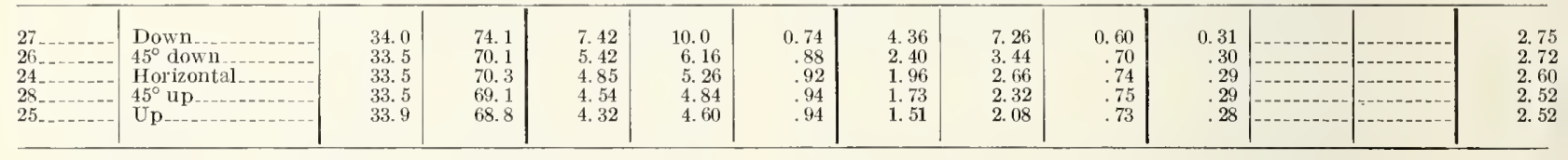

a Repeat of test 20 with foil surfacc painted (pancl 6).

lated on the basis of equal uniform airspaces on the two sides of the blanket, or about 87 percent of the insulating value of $A$. Some of the decrease was due to compression of the blanket at the edges; further, the resistance of the cold airspace was seriously reduced, possibly because the airspace was quite nonuniform in thickness, and probably less than $1 / 2 \mathrm{in}$. thick at the center. In installation $\mathrm{C}$, there was no intentional airspace between the tautly stretched aluminum-foil membrane of the blanket and the panel face, and accordingly, the panel with this installation had less resistance than with installations $\mathrm{A}$ or $\mathrm{B}$. However, there was an observed temperature drop of about $7 \mathrm{deg} F$ from the panel face to the foil in the tests of installation $\mathrm{C}$, which was equivalent to a thermal resistance of about 0.5. A resistance approximately of this magnitude presumably could be expected in field applications similar to $\mathrm{C}$, al though if feasible an installation like $B$ would be preferable.

Test 23 was made to duplicate test 20 , but with the foil surface painted. The resistance between the panel surface plate and the foil was reduced to 0.39 by this change. The large space formed in installation $\mathrm{D}$ made this installation better than or approximately equal to $\mathrm{C}$ in insulating effect, in spite of the reduction of blanket thickness and resistance due to constraint by the taut foil. However, in view of the probability of moisture condensation on the foil under the framing, application D is considered less desirable than the other's.

\section{c. Commercial 2-in. Mineral-Wool Blanket, Foil-En- closed and Kraft-Enclosed}

Tables 7 and 8 present the data obtained with various applications of a typical nominal 2 -in. enclosed blanket insulation in a $7 \frac{5}{8}-$ in. panel. In table 7 , the effects of high and low thermal emittances of the blanket faces are shown; in table 8 , tests of the blanket with various modifications of the breather membrane are presented.

Table 7 shows a considerable variation in the observed blanket resistance, $R$, among the four blanket specimens, ranging from an average of 5.94 for $\Lambda$ to 8.79 for $\mathrm{D}$. The thermal conductivity of the fibrous material, as determined by a guarded hotplate measurement, was $0.259 \mathrm{Btu} / \mathrm{hr}$ $\mathrm{ft}^{2}$ (deg $\mathrm{F} / \mathrm{in}$.) at $73.5^{\circ} \mathrm{F}$ mean temperature, corresponding to a thermal resistance of about 4.0 deg F per $\left(\mathrm{Btu} / \mathrm{hr} \mathrm{ft}^{2}\right)$ per inch of thickness, or 8.1 for a 2 -in. thickness, at the mean temperatures of the panel tests.

There was considerable variation of the thickness of fibrous material from place to place in the 
TABLE 7. Thermal resistance of $75 / 8$-in. panels insulated with commercial 2 -in. mineral-wool blantets, foil enclosed and kraft paper enclosed

Resistances are expressed in deg $\mathrm{F}$ per (Btu/hr $\left.\mathrm{ft}^{2}\right)$

\begin{tabular}{|c|c|c|c|c|c|c|c|c|c|c|c|c|c|}
\hline \multirow{2}{*}{ Test } & \multirow{2}{*}{$\begin{array}{l}\text { Direction of } \\
\text { heat flow }\end{array}$} & \multicolumn{5}{|c|}{ Panel } & \multicolumn{3}{|c|}{ Warm airspace } & \multicolumn{3}{|c|}{ Cold airspace } & \multirow{2}{*}{$\frac{\text { Blanket }}{R}$} \\
\hline & & $\begin{array}{c}\text { Mean } \\
\text { tempera- } \\
\text { ture }\end{array}$ & $\begin{array}{l}\text { Temper- } \\
\text { ature } \\
\text { difference }\end{array}$ & $R$ & $R^{\prime}$ & $R / R^{\prime}$ & $R$ & $R^{\prime}$ & $R / R^{\prime}$ & $R$ & $R^{\prime}$ & $R / R^{\prime}$ & \\
\hline
\end{tabular}

A. Panel 9, foil-enclosed blanket against warm surface $\left(E_{\varepsilon}=0.03\right)$

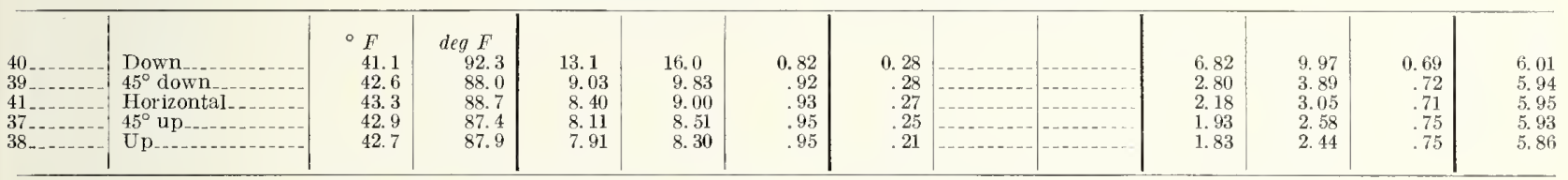

B. Panel 11, blanket from same roll as A; installed with 2-in. warm and 3/2-in. cold airspaces $\left(E_{r}=0.09 ; E_{c}=0.03\right)$

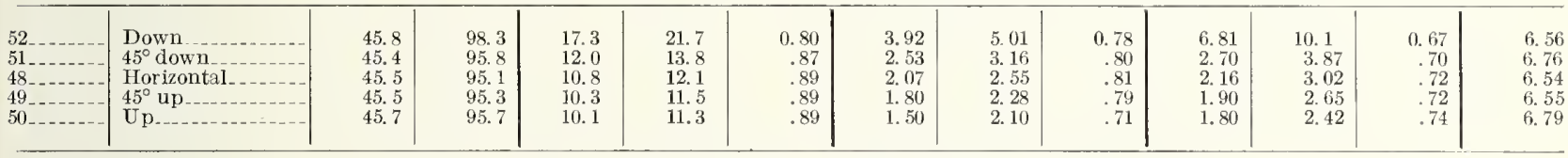

C. Panel 23, foilenclosed blanket from second roll; installed like B $\left(E_{w}=0.09 ; E_{c}=0.03\right)$

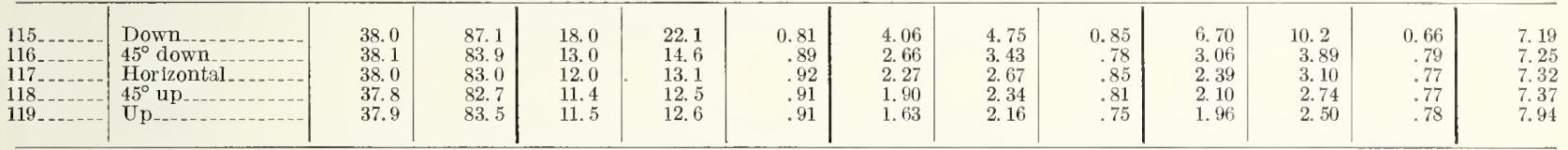

D. Panel 28 , commercial blanket similar to $\mathrm{A}, \mathrm{B}$, and $\mathrm{C}$ but kraft enclosed; installed like $\mathrm{B}\left(E_{w}=0.82 ; E_{c}=0.86\right.$ estimated)

\begin{tabular}{|c|c|c|c|c|c|c|c|c|c|c|c|c|c|}
\hline & Down & 40.1 & 88.0 & 11.4 & 11.4 & 1.00 & 1.02 & 1.01 & 1.01 & 1.57 & 1.55 & 1.01 & 8.81 \\
\hline 138 & $45^{\circ}$ down & 40.2 & 87.7 & 10.8 & 10.8 & 1.00 & .95 & .96 & .99 & 1. 27 & 1. 29 & .98 & 8.58 \\
\hline $139_{-}$ & Horizontal & 40.6 & 87.6 & 10.8 & 10.8 & 1. 00 & .93 & .91 & 1. 02 & 1. 18 & 1. 20 & .98 & 8. 66 \\
\hline 140 & $45^{\circ}$ up & 40.1 & 87.8 & 10.8 & 10.7 & 1.01 & .87 & .86 & 1.01 & 1.18 & 1. 14 & 1.04 & 8.72 \\
\hline $141 \ldots$ & $U p_{\ldots} \ldots$ & 40.5 & 88.6 & 11.1 & 11.1 & 1.00 & .83 & .83 & 1.00 & 1. 10 & 1. 11 & .99 & 9.19 \\
\hline
\end{tabular}

E. Panel 13 , same as B, with warm foil surface painted ( $E_{w}=0.82$ estimated; $E_{c}=0.03$ )

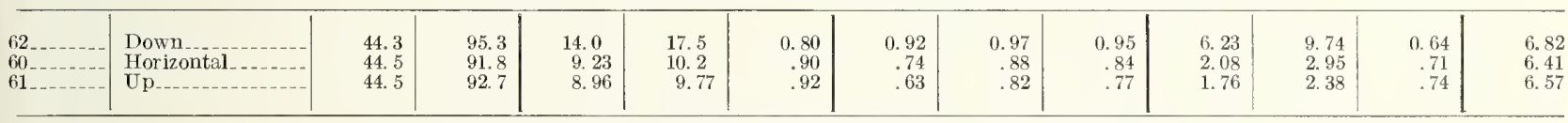

F. Panel 14, same as B, with both foil surfaces painted ( $E_{w}=E_{c}=0.82$ estimated)

\begin{tabular}{|c|c|c|c|c|c|c|c|c|c|c|c|c|c|}
\hline 63 & Down. & 43.8 & 89.5 & 9.58 & 9.69 & 0.99 & 0.91 & 1.00 & 0.91 & 1. 56 & 1.58 & 0.99 & 7.1 \\
\hline & Horizontal & 44.4 & 88.9 & 8. 59 & 8.83 & .97 & .79 & .89 & .89 & 1. 06 & 1. 20 & .88 & 6.74 \\
\hline & $\mathrm{Up}_{-}$ & 45.4 & 90.2 & 8. 41 & 8.77 & .96 & 64 & .82 & .78 & .93 & 1. 11 & .82 & 6.84 \\
\hline
\end{tabular}

several blanket specimens used, as observed upon examination after the tests. Although measurements were made of the thickness of the adjoining airspaces in the various panel installations, the actual thickness of the fibrous material between the blanket membranes could not be ascertained under the test conditions as the pancl orientation was changed. The observed blanket resistances for each specimen indicate slightly different effective thicknesses at different pancl orientations. The greater differences in resistance, among the blankets of parts $\mathrm{A}, \mathrm{B}, \mathrm{C}$, and $\mathrm{D}$, seem attributable to initial compression in the shipped form with variable self-expansion as installed, depending on the constraints imposed by the breather membrane.

The effect of highly reflective blanket surfaces in increasing the insulating value of the applica- tion is indicated only partially by comparison of the observed panel resistances, $R$, for specimens $\mathrm{A}$ to $\mathrm{F}$ in table 7 . The apparent effect shown by this comparison is, in general, less than the real effect, because of the differences in actual blanket resistance - the real effect is shown by adding to a fixed nominal blanket resistance the observed resistances of the airspaces, as taken from the table. The nearest approach to this more appropriate comparison is afforded by the panel resistances of specimens $\mathrm{B}, \mathrm{E}$, and $\mathrm{F}$.

The $R / R^{\prime}$ ratios for the panels were, in general, between 0.89 and 0.95 when one or more panel airspaces had a highly reflective surface, for all directions of heat flow except downward. For this case, panel $R / R^{\prime}$ ratios were approximately 0.8 . When the panel airspaces did not have a highly reflective surface, panel $R / R^{\prime}$ ratios were nearly unity. 
The panel $R / R^{\prime}$ ratios simply reflect the $R / R^{\prime}$ ratios for the two individual airspaces. The warm airspace, when it had a highly reflective surface, had $R / R^{\prime}$ ratios clustering about 0.8 , and when it did not have a highly reflective surface, had $R / R^{\prime}$ values between 0.77 and 1.02 . The warm-side foil of this blanket was imprinted over about 15 percent of its area with lettering, the lettered and unlettered areas having measured emittances of 0.30 and 0.06 , respectively. This was taken into account in calculating the average value of $E$ for the warm airspace as 0.09 ; however, because the printed areas had about 5 times the absorptance of the plain foil for the radiant energy emitted by the other side of the airspace, they probably tended to be at a higher temperature, and thus to affect the normal development of convection currents in the space, depending on the airspace orientation and direction of heat flow.

The $R / R^{\prime}$ ratios in table 7 for the cold airspace with an aluminum-foil surface on its warm side were between 0.7 and 0.8 for all heat flow directions except downwald, for which the values of $R / R^{\prime}$ approximated 0.67 .
In table 8 , specimen $\mathrm{C}_{1}$ was the same blanket as specimen $\mathrm{C}$, with the breather membrane detached from the nailing flange and installed tautly between the framing members, as shown in detail $\mathrm{X}$ of figure 3 . For this application, and especially for the downward heat-flow direction, the $R / R^{\prime}$ ratios for the cold airspace were substantially gieater than the corresponding values for specimen C. A similar improvement is noted in the $R / R^{\prime}$ ratios for the warm airspace for heatflow directions other than downward. These results suggest that irregularities of shape and lower thermal resistance at the flanks of the conventionally installed blanket caused augmentation of convcction currents in the adjoining airspaces, thus decreasing their thermal resistance.

Conduction of heat by the foil of the breather membrane where it passes from the nailing strip on the warm side to the cold side of the blanket might be responsible for some part of the cffect mentioned above. To investigate this possibility, specimen $\mathrm{C}_{2}$ in table 8 was prepared with the same blanket as used in $\mathrm{C}$ and $\mathrm{C}_{1}$, with the perforated foil laminate breather reattached to the nailing

TABLE 8. Thermal resistance of 75/8-in. parels insulated with commercial 2 -in. foil-enclosed mineral-wool blankets with modifications of the breather membrane

Resistances are expressed in deg F per (Btu/hr ft ${ }^{2}$ )

\begin{tabular}{|c|c|c|c|c|c|c|c|c|c|c|c|c|c|}
\hline \multirow{2}{*}{ Test } & \multirow{2}{*}{$\begin{array}{c}\text { Direction of } \\
\text { heat flow }\end{array}$} & \multicolumn{5}{|c|}{ Panel } & \multicolumn{3}{|c|}{$\begin{array}{l}\text { Warm airspace, } \\
2 \text { in. }\end{array}$} & \multicolumn{3}{|c|}{$\begin{array}{c}\text { Cold airspace, } \\
31 / 2 \text { in. }\end{array}$} & \multirow{2}{*}{ Blanket } \\
\hline & & $\begin{array}{c}\text { Mean } \\
\text { tempera- } \\
\text { ture }\end{array}$ & $\begin{array}{l}\text { Temper- } \\
\text { ature } \\
\text { difference }\end{array}$ & $R$ & $R^{\prime}$ & $R / R^{\prime}$ & $R$ & $R^{\prime}$ & $R / R^{\prime}$ & $R$ & $R^{\prime}$ & $R / R^{\prime}$ & \\
\hline
\end{tabular}

C. Panel 23 (data from part C of table 7 repeated)

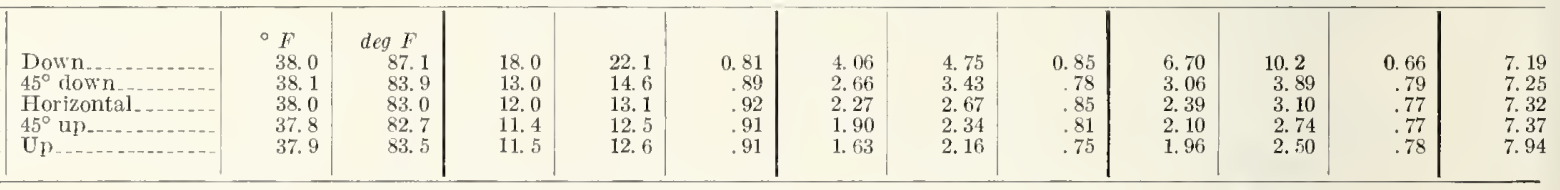

$C_{1}$. Panel 24, breather removed from blanket edges of panel 23 and stapled tautly to framing $\left(E_{w}=0.09 ; E_{c}=0.03\right)$

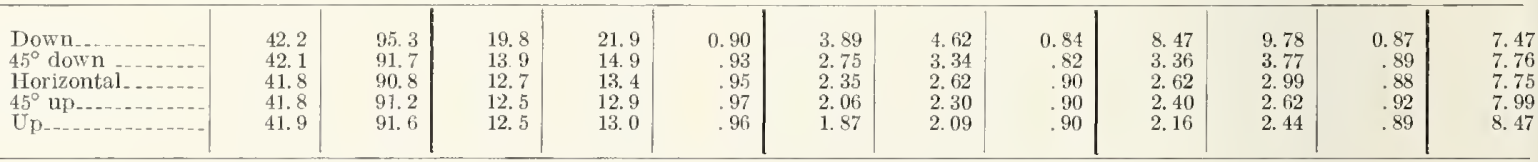

C2. Panel 25, foil removed at edges of breather (see note $p$ of table 1$)\left(E_{w}=0.09: E_{c}=0.03\right.$ )

\begin{tabular}{l|l}
41.9 & 94.5 \\
41.8 & 91.3 \\
41.9 & 91.1 \\
42.0 & 91.5 \\
42.1 & 92.3
\end{tabular}

\begin{tabular}{l|l}
18.7 & 22.5 \\
12.9 & $\mathbf{1 4 . 7}$ \\
12.2 & $\mathbf{1 3 . 3}$ \\
12.1 & 12.9 \\
12.3 & 13.0
\end{tabular}

0.83
.88
.92
.94
.95

4.09
2.56
2.28
2.00
1.74

\begin{tabular}{l|r|}
4.63 & 0.88 \\
3.35 & .76 \\
2.61 & .87 \\
2.30 & .87 \\
2.11 & .83 \\
\hline
\end{tabular}

\begin{tabular}{c|c|}
6.73 & 10.1 \\
2.88 & 3.87 \\
2.36 & 3.08 \\
2.15 & 2.68 \\
2.13 & 2.43
\end{tabular}

0.67
.74
.77
.80
.88

$\mathrm{C}_{3}$. Pand 26, same as $\mathrm{C}_{2}$ but with breather ends sealed to framing $\left(E_{w}=0.09 \cdot E_{e}=0.03\right)$

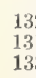

$$
\begin{aligned}
& \text { Down } \\
& \text { Horizontal } \\
& \text { Up }
\end{aligned}
$$

\begin{tabular}{l|l|}
41.8 & 94.8 \\
41.9 & 91.7 \\
41.9 & 92.3 \\
\hline
\end{tabular}

\begin{tabular}{l|l|}
18.8 & 22.5 \\
12.6 & 13.4 \\
12.4 & 13.0 \\
\hline
\end{tabular}

0.84
.94
.95

\begin{tabular}{l|l|}
3.99 & 4.63 \\
2.30 & 2.63 \\
1.77 & 2.11
\end{tabular}

0.86
.87
.84

7.00
2.59
2.20

\begin{tabular}{c|}
10.0 \\
2.99 \\
2.41
\end{tabular}

\begin{tabular}{l|l}
0.70 & 7.81 \\
.87 & 7.74 \\
.91 & 8.48
\end{tabular}

$C_{4}$. Panel 27, perforated foil breather replaced by reflective paper breather $\left(E_{w}=0.09 ; E_{c}=0.20\right)$

$$
\begin{aligned}
& \text { Down } \\
& \text { Uporizontal } \\
& \text { Up. }
\end{aligned}
$$

\begin{tabular}{l|l|}
39.9 & 91.0 \\
40.1 & 88.2 \\
40.2 & 89.5
\end{tabular}

16.8
12.1
12.2

18.0
12.6
12.9

0.93
.96
.95

\begin{tabular}{l|} 
4. 39 \\
2.34 \\
1.76
\end{tabular}

\begin{tabular}{r|r|}
4.95 & 0.89 \\
2.62 & .89 \\
2.09 & .84
\end{tabular}

4. 11
2. 01
1. 68

4.75
2.16
2.00


strip after the foil had been removed from the flank area (between the arrows shown in detail Y of fig. 3). The $R / R^{\prime}$ ratios for both airspaces were greater for specimen $\mathrm{C}_{2}$ than for specimen $\mathrm{C}$ for the upward heat-flow directions, - indicating a slight improvement when the foil was removed at the flank. The average resistance of the blanket for $\mathrm{C}_{2}(7.86)$ was about 5 percent greater than for $\mathrm{C}(7.41)$, but not significantly different from that for $\mathrm{C}_{1}(7.89)$, which also did not have aluminum foil passing around the edge of the blanket. However, the $\mathscr{R} / R^{\prime}$ ratios for the airspaces, particularly the cold airspace, were in general less for specimen $\mathrm{C}_{2}$ than for specimen $\mathrm{C}_{1}$, suggesting that the greater irregularity of shape of the cold space with specimen $\mathrm{C}_{2}$ than with $\mathrm{C}_{1}$ had some effect in lowering its thermal resistance.

For all of the previous tests of this blanket, except $C_{1}$, the breather membrane was not sealed to the framing at the top and bottom, in accordance with ordimary installation practice. For the tests of $\mathrm{C}_{3}$, the breather ends of specimen $\mathrm{C}_{2}$ were sealed to the framing with aluminum tape, thus preventing circulation of air between the fibrous material and the cold airspace except through the minute breather perforations. The $R / R^{\prime}$ ratio for the cold airspace for horizontal heat flow (for which circulation would be a maximum) was, for $\mathrm{C}_{3}$, substantially the same as for $\mathrm{C}_{1}$, and greater than the value of 0.77 for other specimens with the reflective breather unsealed at top and bottom. The blanket resistance for specimen $\mathrm{C}_{3}$ for horizontal heat flow also agreed with that for $C_{1}$ and, in general, was greater than the values obtained in the tests with the breather unsealed.

Specimen $\mathrm{C}_{4}$ had a laboratory-applied breather membrane of kraft paper reflectively coated on the cold side. The measured emittance of the reflective side was 0.20 , yielding a cold airspace radiation interchange factor of 0.20 . Comparison of the resistance of the cold airspace for specimen $\mathrm{C}_{4}$ with the values for corresponding heat-flow directions for specimens B, D, E, and F of table 7, and $\mathrm{C}$ and $\mathrm{C}_{2}$ of table 8 , shows that the airspace with a reflectively coated paper breather had in general less resistance than a similar space with an aluminum-foil breather, but considerably more resistance than a space without a reflective surface, especially for downward heat flow.

\section{Summary of Results}

1. Observed insulating values for panels were in agreement with calculated values within 10 percent or better in almost all cases where the airspace conditions conformed to those of the exemplary spaces with which the original data were obtained. (Calculated values for panels containing fibrous insulations were based on observed rather than estimated values of the thermal resistance of the fibrous component.)
Significantly wider departures of observed from calculated values for panels were observed as a result of such factors as condensation of moisture on reflective surfaces, lack of uniformity of airspace thickness, air circulation between tandem airspaces, and effects attributed to local high conductance at edges of insulating blankets or radiation from framing members.

2. Condensation of moisture on reflective surfaces decreased the insulating effect of an airspace. The decrease observed ranged from 30 percent for a horizontal airspace with downward heat flow to 10 percent for other orientations. Condensation on a reflective membrane used in a critical position can be avoided by making the membrane adequately vapor permeable.

3. The insulating effect of tandem wedgeshaped airspaces formed by an internediate oblique highly reflective membrane was materially less than that of airspaces uniformly of the same average thickness. The reduction of thermal resistance varied approximately linearly with the departure of the wedge-shaped airspace from uniformity of thickness. For the tandem wedge-shaped spaces formed by aluminum foil stretched diagonally from the front to back faces of adjacent 2 by 4 studs on 16-in. centers, the observed resistances were 53,75 , and 78 percent of those calculated for tandem uniformly thick spaces formed by a foil membrane midway between the panel faces, when heat flow was downward, horizontal, and upward, respectively.

4. Circulation of air between tandem airspaces through three holes near each end of the dividing aluminum-foil membrane caused reductions of 18 and 12 percent in the insulating effect of the airspaces when they were vertical or at a $45^{\circ}$ angle, respectively. The holes were 0.58 in. square, and at each end totaled $1 \mathrm{in}^{2}$ in area in a membrane 30 in. wide. No significant loss of insulating effect was observed when the airspaces were horizontal.

5. It is shown that minute perforations in a highly reflective alumimum-foil membrane dividing two tandem airspaces, intended to make it vapor permeable, decrease the insulating effect of the membrane as a result of radiation through the apertures. The perforations, in the case described, increase the effective radiation interchange factor of each of the airspaces by an amount approximately equal to twice the fractional area of the apertures. The reduction in airspace resistance from this cause depends on orientation and direction of heat flow, and is estimated to range from about 20 percent for downward heat flow to about 5 percent for upward heat flow for a membrane having 64 perforations per square inch, totaling 1.6 percent of the area. Air circulation through the perforations described had no appreciable effect on the insulat- 
ing value of the two adjoining airspaces, in any orientation.

6. Tests of tandem airspaces, each 3.8 in. thick and $14.4 \mathrm{in}$. wide, indicated that the thermal resistance of a thick airspace with one reflective surface may depend to some extent on the position of that surface because of effects due to radiation from the sides of the framing.

7. Comparison of observed and calculated resistances for panels insulated with a board-type fibrous insulation of uniform thickness, without and with reflective surfaces on the board, indicated agreement within 7 percent, and considerably better in most cases. Observed resistances for individual airspaces agreed with the calculated values within 6 percent in 13 of the 15 cases in which aluminum foil was applied to the board insulation.

8. For $7 \frac{5}{8}-$ in. panels insulated with 2 -in. mineral-wool aluminum-foil-enclosed blanket insulation in approximate midspace, observed resistances were within about 10 percent of the calculated values, except for cases of downward heat flow, in which departures of about 20 percent were found. Observed resistances for individual airspaces were in a few extreme cases as much as 30 percent lower than calculated values, the departures being attributed chiefly to the effects of nonumiform thickness and conductance of the blanket as installed. The reduction of thickness and conductance of the blanket was especially great at the flanks near framing members. For the four samples of nominal 2 -in. blanket insulation used, observed blanket resistances differed by about 40 percent.

9. Tests with four different applications of a 1/1/4-in. low-density mineral-wool blanket with ahuminum foil on its warmer side showed that applications with the blanket in midspace of the panel, or bowed into the space from the warm side, were materially more effective than those in which it was stretched tautly over the warm or cold faces of the framing members.

The authors acknowledge with appreciation the services of Mervin M. Mosley, who made the inajority of the test-panel installations and conducted the panel measurements, and Thomas W. Watson, who measured the thermal conductivity of the fibrous blankets by the guarded hotplate method, and determined the emittance of some of the surfaces of the various airspaces. They also thank James L. Brandt (Aluminum Company of America) for additional cmittance determinations.

\section{Appendix}

\subsection{Method of Calculating Airspace Conduc- tances}

It is convenient to consider that the transfer of heat between the warmer and the cooler surfaces of an airspace takes place by radiation, and by convection and conduction combined. The heat transfer by radiation depends only upon the absolute temperatures of the surfaces bounding the airspace, and upon a radiation interchange factor that takes account of the geometry of the space and of the emittances of its surfaces. It does not depend on the orientation of the airspace or direction of heat flow. The heat transfer by convection and conduction combined, however, depends on a number of factors, such as the orientation of the airspace and the direction of heat flow, the temperature difference across the airspace, its dimensions, and its mean temperature.

It was postulated that for given airspace surface temperatures, the two components of the total heat transfer are independent of each other, and therefore, that the calculated thermal conductance, or coefficient for the total heat transfer across an airspace by all modes combined, $C^{\prime}$, can be expressed as the sum of two independent coefficients, as indicated by the equation

$$
C^{\prime}=E h_{r}+h_{c} .
$$

The two terms on the right-hand side of eq (1) represent, respectively, the radiation coefficient and the coefficient for combined convection and conduction.

\section{a. Radiation Coefficient}

The coefficient for heat transfer by radiation across an airspace, per unit of temperature difference of its surfaces, is given by $E h_{\tau}$, where $E$ is the radiation interchange factor referred to above and described below, and $h_{\tau}$ is obtained (in Btu/hr $\mathrm{ft}^{2}$ (deg F)) from the Stefan-Boltzmann law as follows:

$$
\begin{aligned}
h_{r} & =\frac{0.172 \times 10^{-8}\left(T_{1}^{4}-T_{2}^{4}\right)}{\left(T_{1}-T_{2}\right)} \\
& =0.00686\left(\frac{T_{m}}{100}\right)^{3} \text { approx. }
\end{aligned}
$$

$T_{1}$ and $T_{2}$ are the absolute temperatures $\left(^{\circ} \mathrm{F}+\right.$ $460^{\circ}$ ) of the warmer and cooler surfaces, respectively, of the airspace, and $T_{m}$, the mean temperature of the airspace, equals $\frac{1}{2}\left(T_{1}+T_{2}\right)$. Values of $h_{\tau}$ for various airspace mean temperatures (expressed in $\operatorname{deg} \mathrm{F}$ ) are given in figure 5 .

The radiation in terchange factor, $E$, is calculated by means of the equation

$$
\frac{1}{E}=\frac{1}{e_{1}}+\frac{1}{e_{2}}-1,
$$

where $e_{1}$ and $e_{2}$ are the total hemispherical emittances of the warm and cold surfaces of the airspace. Equation (3) applies rigorously for the case of parallel planes of infinite extent. For parallel facing rectangles of limited area, the direct radiation interchange factor between them be- 


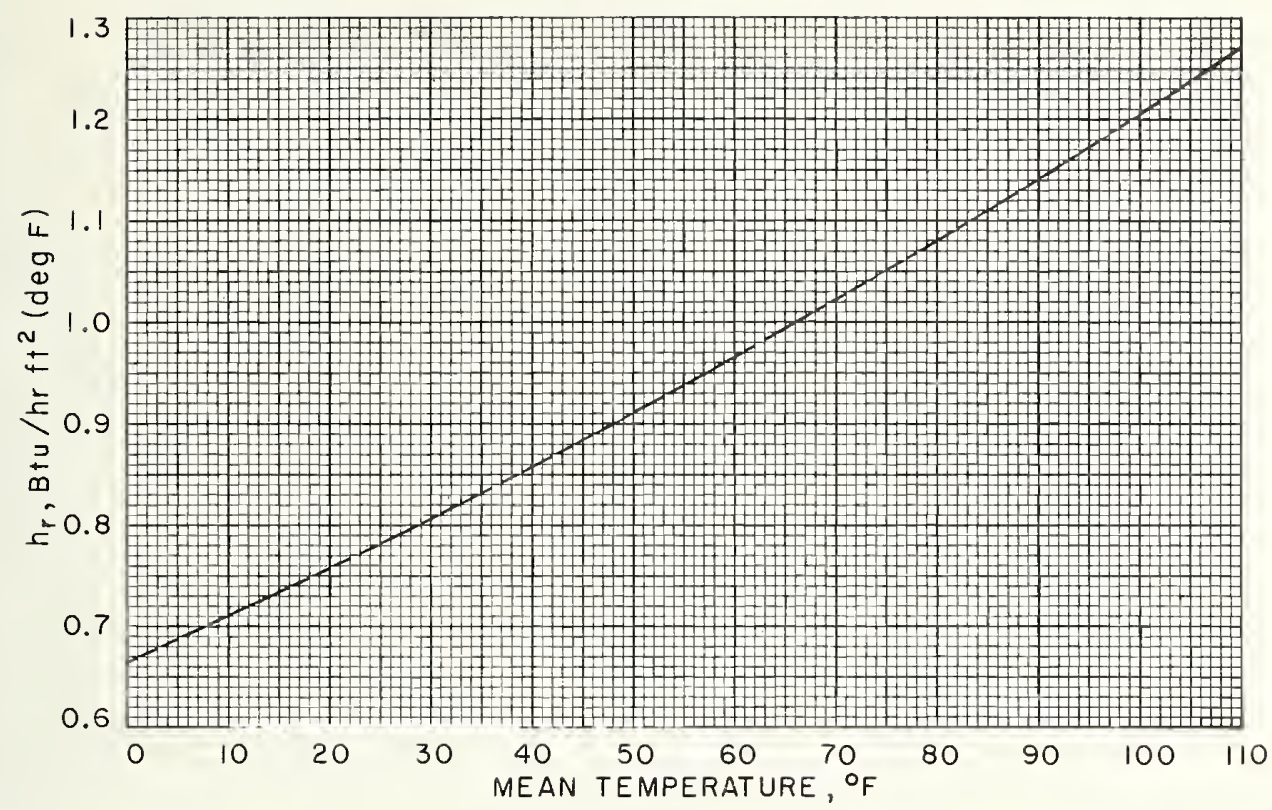

Figure 5. Linear radiation coefficient for heat transfer across an airspace, for a radiation interchange factor, $E$, of unity.

comes less than the value given by eq (3) as the spacing between them increases. However, as the spacing increases, reradiation between the faces and side boundaries of an airspace partially offsets the decrease of the factor. Procedure for obtaining the radiation interchange factor between gray source-sink surfaces forming part of an enclosure, with reradiation taken into account, has been given by Hottel. ${ }^{4}$

When the value of $E$ as computed by eq (3) is small (less than 0.2), it differs very little from the factor obtained by the more elaborate procedure given by Hottel, for airspaces of the dimensions under consideration. For an airspace of long rectangular shape, such as the space between framing members on 16-in. centers, with facing surfaces of high emittance $(0.9)$ spaced 4 in. apart, for which the value of $E$ as computed by eq (3) would be 0.82 , the cited procedure yields a value of about 0.72. For this rather extreme case, the error in resistance introduced by using eq (3) for computing $E$ would be approximately 10 percen $t$ for a space having a total resistance of 0.8 to 1.2 deg $\mathrm{F}$ per $\left(\mathrm{Btu} / \mathrm{hr} \mathrm{ft}^{2}\right.$ ), depending on temperatures, orientation, and direction of heat flow. 'The overall error in computing the insulating effect of a typical wall or section introduced by the above error is negligible from a practical point of view. Thus, for purposes of practical use and simplicity, values of the radiation interchange factor, $E$, as computed by eq (3), seem adequate.

\section{b. Coefficient for Combined Convection and Conduction}

Values of the coefficient for heat transfer by convection and conduction combined $\left(h_{c}\right.$ in eq (1)) had to be determined experimentally.

\footnotetext{
${ }^{4}$ W. H. McAdams, Heat transmission, 3d ed., eq (4-33), p. 76 (Mectraw-
}

To do this, 96 heat-transfer measurements were made in the rotatable hotbox apparatus deseribed in this report on a number of 5.4- by 8 -ft panels with sheet-metal faees enclosing 1 or 2 tandem airspaces of uniform thicknesses from $\frac{5}{8}$ to $3^{3 / 8} \mathrm{in}$. All of the airspaces had one or more highly reflective surfaces yielding values of $E$ on the order of 0.03 . The measurements were made for five different conditions of panel orientation and direction of heat flow: Horizontal, with downward heat flow; $45^{\circ}$ from the vertical, with downward heat flow; vertical, with horizontal heat flow; $45^{\circ}$, with upward heat flow; and horizontal, with upward heat flow.

The results, after slight corrections to take account of heat conduction in the wood framing that formed the lateral boundaries of the 32- by 60 -in. test airspace located centrally in the panel. yielded experimental values of the total thermal conductance of the airspace or spaces corresponding to the test conditions. Upon subtracting the calculated radiation component, $E h_{\tau}$, from the total coefficient, values of $h_{c}$ for particular test conditions were obtained.

Using dimensional analysis, the results were reduced to the form presented in figure 6 . A separate curve based on the data is given for each panel orien tation and direetion of heat flow, using logarithmic coordinate paper. These relate values of the product $h_{c} l$ to values of $\theta l^{3}$, for an arbitrarily selected value of $50^{\circ} \mathrm{F}$ for the mean temperature of the airspace, where $l$ is the thiekness of the airspace in inches, and $\theta$ is the temperature difference across it, in deg. F. The dashed horizontal line corresponds to the case of conduction only, with no heat transfer by con vection; the value of $\left(h_{c} l\right)_{50}$ for this line $(0.175)$ is the thermal conductivity of still air at $50^{\circ} \mathrm{F}$ as determined by 


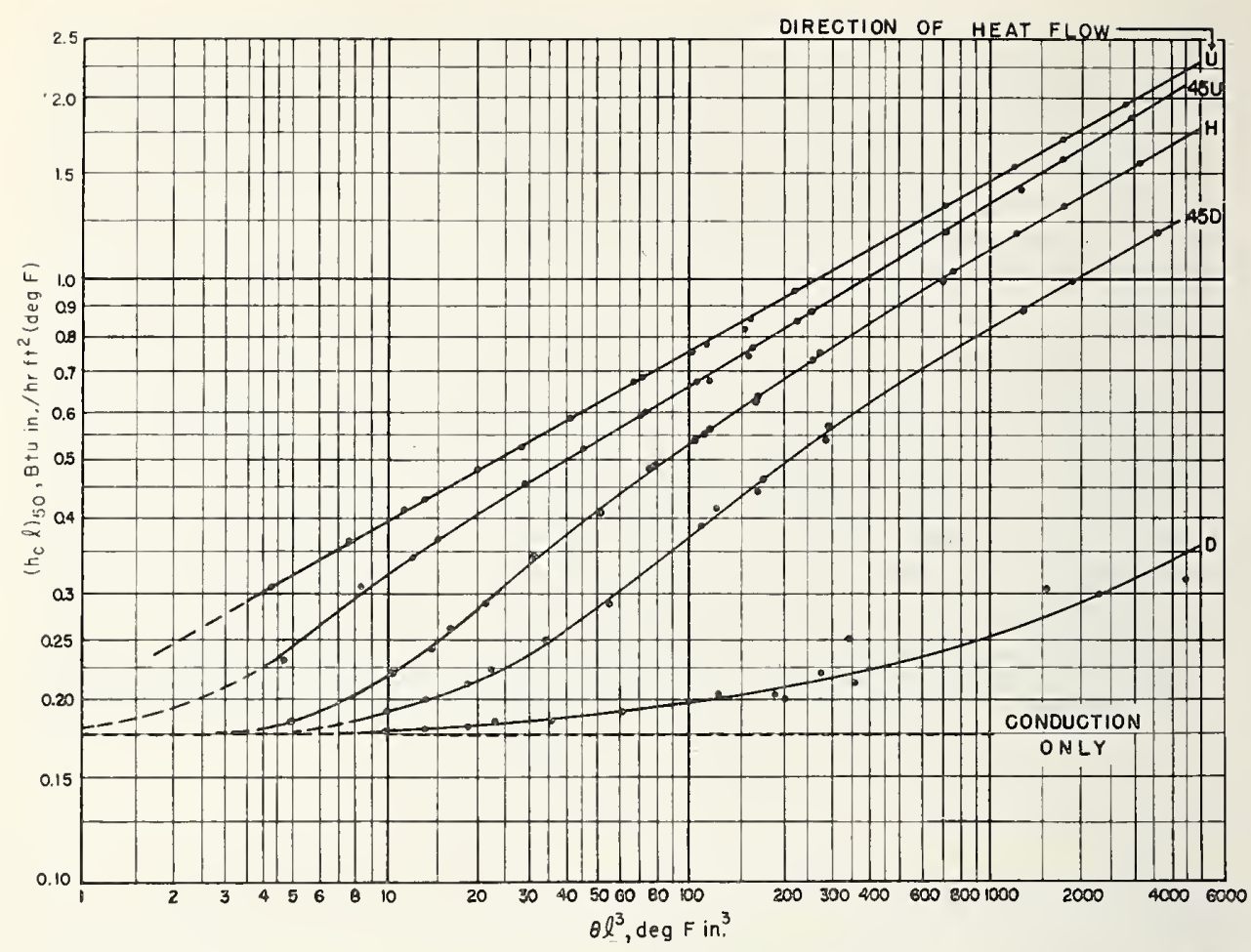

FinuRE 6. Convection-conduction coefficient for heat transfer across an airspace, for five orientations of the airspace and directions of heat flow.

the trend of the test data at low values of $\theta l^{3}$.

The effect of the mean temperature of the airspace on the value of $h_{c}$ depends upon whether convection is a significant factor in the lieat transfer. Consideration of the variations with temperature of the properties of air involved in conduction and in natural convection (thermal conductivity, thermal expansion, and kinematic riscosity), indicated the practicability of adjusting values of $\left(h_{c}\right)_{50}$ to values for other moderately different mean temperatures by means of the approximate equations: For $\left(h_{c} l\right)_{50}>0.3$,

$$
\left(h_{c}\right)_{t}=\left(h_{c}\right)_{50}[1-0.001(t-50)],
$$

and for $\left(h_{c} l\right)_{\overline{0} 0}<0.2$,

$$
\left(h_{c}\right)_{l}=\left(h_{c}\right)_{50}[1+0.0017(t-50)] .
$$

For intermediate values of $\left(h_{c} l\right)_{50}$, the temperature coefficient in the above equations is variable, and passes through zero in value, so that mean temperature has little effect on $h_{c}$.

To investigate the practical application of $\mathrm{eq}$ (1), which was postulated, 50 measurements were made with panels containing one or more airspaces for which the radiation interchange factor $E$, as computed by eq (3), had values from about 0.2 to 0.76 . Values of $\left(h_{c} l\right)_{50}$ were obtained from the results in the same manner as those described above. These values were divided by values of $\left(h_{c} l\right)_{50}$ taken from the curves of figure 6 at the corresponding values of $\theta l^{3}$. The average value of the 50 quotients so obtained was 1.009 . The limits of the average quotient, determined for a 95 -percent confidence interval for a group of 50 values, were found to be 1.028 and 0.989 . These limits bracket closely the value 1.000 , thereby establishing the practical utility of eq (1).

\subsection{Range of Experimental Conditions at Which Convection-Conduction Coefficients Were Determined}

The data shown by the plotted poin ts of figure 6 were obtained with airspaces of uniform thickness, with surfaces of moderate flatness and smoothness, and with no leakage of air into or out of the spaces or between spaces where two tandem spaces were used. The average temperature gradient of the surfaces of the test panel bounding the test airspaces, in the direction of its length, was not greater than about $0.2 \mathrm{deg} \mathrm{F} / \mathrm{ft}$ for each $\mathrm{Btu} / \mathrm{hr}$ $\mathrm{ft}^{2}$ of heat transfer across the airspace.

The test airspaces were approximately $60 \mathrm{in}$. in height or length, and $32 \mathrm{in}$. wide; the spaces ranged in thickness from $5 / 8$ to $3 \frac{3 / 8}{}$ in. In the various measurements by which the plotted points were obtained, the temperature difference across a space ranged from 15 to $119 \mathrm{deg} \mathrm{F}$, and airspace mean temperature ranged from $17^{\circ}$ to $112^{\circ} \mathrm{F}$. The surface emittances of the two facing surfaces of the airspaces, as determined by separate measurements, had values of 0.03 and 0.83 , or 0.03 and 0.03 .

Washington, July 19, 1957. 


\title{
BUILDING MATERIALS AND STRUCTURES REPORTS
}

\author{
[Continued from cover page II]
}

BMS38

13MS39

BMS40

BMS41 BMS42

BMS48

BMS44

BMS45

BMS46

BMS47

BMS48

BMS49 BMS50

BMS51

BMS52

BMS58

BMS54

BMS55

BMS56

BMS57

BMS58

BMS59

BMS60

BMS61

BMS62

BMS68

BMS64

BMS65

BMS66

BMS67

BMS68

BMS69

BMS70

BMS71

BMS72

BMS78

BMS74

BMS75

BMS76

BMS77

BMS78

BMS79

BMS80

BMS81

BMS82

BMS83

BMS84

BMS85

BMS86

BMS87

BMS88
Structural Properties of Two "Dunstone" Wall Constructions Sponsored by the W. E. Dunn Manufacturing Co Structural Properties of a "Wall Construction of "Pfeifer Units" Sponsored by the Wisconsin Units Co Structural Properties of a Wall Construction of "Knap Concrete Wall Units" Sponsored Effect of Heating and Cooling on the Permeability of Masonry Walls Structural Properties of Wood-Frame Wall and Partition Construction with "Celotex" Insulating Boards Sponsored by The Celotex Corporation . . . . Performance Test of Floor Coverings for Use in Low-Cost Housing: Part 2 ..... Surface Treatment of Steel Prior to Printing . . . . . Air Infiltration Through WindowsFloors, and Roofs Sponsored by The Globe-Wernicke Co
Structural Properties of Prefabricated Wood-Frame Constructions for Walls, Parti-
tions, and Ploors Sponsored by American Houses, Ine. tions, and Doors Sponsored by American Houses, Inc.Sponsored by the Homasote Co...

Metallic Roofing for Low-Cost House Construction Stability of Fiber Building Boards as Determined by Accelerated Aging Structural Properties of "Tilecrete Type A" Floor Construction Sponsored by the Tilecrete do

Effect of Ceiling Insulation Upon Summer Comfort Structural Properties of a Masonry Wall Construction of "Mualock Dry Wall Brick" Sponsored by the Munlock. Engineering $\mathrm{CO}_{0} \ldots \ldots$ Fifect of Soot on the Rating of an Oil-Fired Heating Boiler Effects of Wetting and Drying on the Permeability of Masonry Walls A Survey of Humidities in Residences .

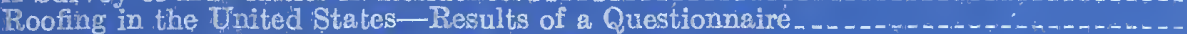
Strength of Soft-Soldered Joints in Copper Tubing- . Properties of Adbesives for Dloor Coverings $\ldots$ Strength, Absorption, and Resiatance to Iaboratory Treezing and Thawing of Building Bricks Produced in the United States. Structural Properties of a Precast Joist Concrete Floor Construction Sponsored by the Portland Cement Association.

Moisture Condensation in Building. Wails Solar Heating of Various Surfaces Methods of Estimating Loads in Plumbing Systemas Plumbing Manual - Structiral Properties of "Mu-Steel" Prefabricated Sheet-Steel Constructions for Walls, Partitions, Floors, and Roofs Sponsored by Herman A. Mugler

Performance Test for Wloor Covering for Use in Low-Cost Housing: Part 3 Stability of Tiber Sheathing Boards as Determined by Accelerated Aging

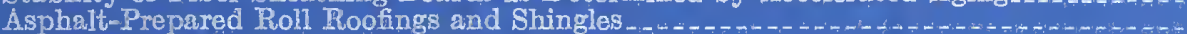
Wire Tests of Wood-and Metal-Framed Partitions Structural Properties of "Precision-Built, Jx." Prefabricated Wood-Frame Wall Construction Sponsored by the Homasote Co

Tndentation Characteristics of Thloor Coverings. S. S. Panelbilt" Prefabricated SheetSteel Constructions for Walls, Paxtitions, and Roofs Sponsored by the Tennessee Coal, Iron \& Railroad Co

Survey of Roofing Materials in the North Central States

Diffeet of Outdoor Bxposure on the Water Permeability of Masonry Walls Properties and Performanne of Wiber Tile Boards Structural, Heat-Transfer, and Water-Permeability Properties of Five Earth-Wall Constructions.

Water-Distributing Systems for Buivding

Performance Test of Floor Cowerings for Use in Low-Cost Housing: Part 4

Field Inspectors' Check List for Building Construetions (eloth cover $5 \times 27 / 2$ inches)

Water Permeability of Walls Built of Masonry Units

Strength of Sleeve Joints in Copper Tubing Made With Various Iead-Base Solders

Survey of Roofing Materials in the South Central States

Temperature Structural, Heat-Transfer, and Water-Permeability Properties of "Speedbrik" Wall Construction Sponsored by the General Shale Products Corporation

A Method for Developing Specifications for Building Construction-Report of Subcommittee on Specifieations of the Central Housing Comanittec on Research,

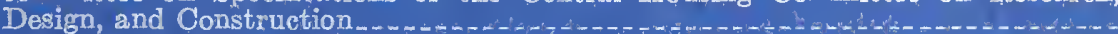
Recommended Building Code Requirements for New Dwelling Construction With Special Reference to War Housing

*

2
$10 \phi$

$10 \%$

$*$

*

$*$

$*$

$*$

$15 \phi$

*

$*$

$10 \%$

$15 \psi$

$*$

*

$10 \%$

$40 \%$

208

$10 \phi$

200

$*$

$20 d$

*s

*. 


\title{
BUILDING MATERIALS AND STRUCTURES REPORTS
}

\author{
[Continued from cover page III]
}

BMS89

BMS90

BMS91

BMS92

BMS93

BMS94

BMS95

BMS96

BMS97

BMS98

BM\$99

BMS100

BMS101

BMS102

BMS103

BMS104

BMS105

BMS106

BMS107

BMS108

BMS109

BMS110

BMS111

BMS112

BMS113

BMS114

BMS115

BMS116

BMS117

BMS118

BMS119

BMS120

BMS121

BMS122

BMS123

BMS124

BMS125

BMS126

BMS127

BMS128

BMS129

BMS 130

BMS131

BMS132

BMS133

BMS134

BMS135

BMS136

BMS 137

BMS138

BMS139

BMS140

BMS141

BMS142

BMS143

BMS144

BMS145

B MS146

B MS147

BMS148

BMS149

BMS150

BMS151
Structural Properties of "Precision-Built, Jr." (Second Construction) Prefabricated Wood-Frame Wall Construction Sponsored by the Homasote Co
Structural Properties of "PHC" Prefabricated Wood-Framo Constructions for Walls, Floors, and Roofs Sponsored by the PHC Housing Corporation A Glossary of Housing Termis.

Fire-Resistance Classifications of Building Constructions.

Accumulation of Moisture in Walls of Frame Coastruction During Winter Exposure.

Water Permeability and Weathering Resistance of Stucco-Faced, Gunite- Fraced, and "Krap Concrete-Unit" Walls

Tests of Cement-Water Paints and Other Waterproofings for Unit-Masorary Walls

Properties of a Porous Concrete of Cement and Uniform-Sized Gravel.

Dixperimental Dry-Wall Construction With Fiber Insulating Bosrd.

Physical Properties of Terrazzo Aggregates.

Structural and Heat-Transfer Properties of "Multiple Box-Girder Pyywood Parela" for Walls, Floors, and Roofs

Relative Slipperiness of Floor and Deck Surfiges

Strength and Resistance to Corrosion of Ties for Cavity Walls.

Painting Steel.

Measurements of Heat Losses From Slab Floors

Structural Properties of Prefabricated Plywood Jightweight Constructions for. Walls, Partitions, Hloors, and Roofs Sponsored by the Douglas Fir Plywood Aseociation.

Paint Manual with particular reference to Federal Specifications

Laboratory Observations of Condensation in Wall Specimens.

Temperature Distribution in a Test Bungalow With Various Heating Devices.

Strength of Houses: Application of Bngineering Principles to Structural Design.

Paints for Bxterior Masonry Walls

Performance of a Cosl-Fired Boiler Converted to Oil

Properties of Some Lightweight-Aggregate Concretes With and Without an Air Fintraining Admixture. Fire Resistance of Structural Clay Tile Partitions

A Study of a. Baseboard Convector Heating System in a Test Bungalow.

Preparation and Revision of Building Codes.

Fire Resistance of Walls of Lightweight Aggregate Concrete Masonry Units

Stack Venting of Plumbing Fixtures.

Wet Venting of Plumbing Fixtures

Investigation of Failures of White-Coat Plasters

Physical Properties of Some Samples of Asbestos-Cement Siding

Fire Tests of Wood-Framed Walls and Partitions With Asbestos-Cement Facings.

Fire Tests of Steel Columns Protected With Siliceous Aggregate Conorete.

Stone Bxposure Test. Wall

The Self-Siphonage of Fixture Traps

Effect of Aging on the Soundness of Regularly Hydrated Dolomitic I Ime Putties

Atmospheric Exposure Tests of Nailed Sheet Metal Building Materials.

Fire Bndurance of Shutters for Moving-Stairway Openings

Methods and Fquipment for Testing Printed-Tuamel Felt-Base Floor Coveriag -

Fíre Tests of Gunite Slabs and Partitions -

Capacities of Plumbing Stacks in Buildings.

Live Loads on Floors in Buildings.

Fire Resistance of Concrete Floors.

Fire Tests of Steel Columns Encased With Gypsum Lath and Plaster

Properties of Cavity Walls.

Influence of the Wash From Bronze on the Weathering of Marble-

Bffect of Fdge Insulation Upon Temperature and Condensation on Concrete-Slab Floors

Studies of Stone-Setting Mortans

Second Edition, Selected Bibliography on Building Construction and Maintenance.
Fire Endurance of Open-Web Steel Joist Floom. With Concrete Slabs and Gypsum Ceilings.

Frost Closure of Roof Vents

Fire Tests of Brick Walls.

Sound Insulation of Wall and Floor Constructions

Supplement to BMS144, Sound Insulation of Wall, Floor, and Door Constructions.

Fire Bffects and Fire Control in Nitrocellulose Photographic-Film Storage

Plasticity and Water Retentivity of Hydrated Limes for Structural Purposes.

Effects of Mineral Additives on the Durability of Coating-Grade Roofing Asphalts:-

Fifteen-Year Bxposure Test of Porcelain Enamels.

Combustible Contents in Buildings.

Methods of Testing Small Rire Ixtinguishers

Thermal Resistance of Airspaces and Fibrous Insulations Bounded by Refiective Surfaces.

$$
1
$$

